\title{
Perfil del docente inclusivo de básica primaria: orientado a la transformación del proceso formativo en las instituciones educativas oficiales del distrito de Cartagena-Colombia
}

\author{
Gabriel Román-Meléndez ${ }^{1 *}$, Eufrasio Pérez-Navío² y Antonio Medina-Rivilla ${ }^{3}$ \\ (1) Facultad de Educación, Universidad Tecnológica de Bolívar, Parque Industrial y Tecnológico Carlos Vélez Pombo Km.1 \\ Vía a Turbaco 130001. Cartagena - Colombia. (Correo-e: groman@utb.edu.co) \\ (2) Facultad de Humanidades y Ciencias de la Educación, Dpto. de Pedagogía. Universidad de Jaén, Campus Las \\ Lagunillas, s/n, 23071. Jaén - España. (Correo-e: epnavio@ujaen.es) \\ (3) Facultad de Educación, Dpto. de Didáctica, Organización y Didácticas Especiales, (UNED), C/Juan del Rosal, 14. 28040. \\ Madrid-España. (Correo-e: amedina@edu.uned.es)
}

${ }^{*}$ Autor a quien debe ser dirigida la correspondencia

Recibido Sep. 11, 2020; Aceptado Nov. 9, 2020; Versión final Ene. 6, 2021, Publicado Abr. 2021

\begin{abstract}
Resumen
El objetivo del presente estudio es definir el perfil del docente inclusivo de básica primaria de instituciones educativas del Distrito de Cartagena, Colombia. Participaron 91 docentes pertenecientes a seis escuelas oficiales. El estudio tiene un diseño mixto soportado por los enfoques cuantitativo y cualitativo. Se aplica un cuestionario ad hoc a docentes y una guía orientadora de preguntas a grupos focales de docentes y profesionales de apoyo especializado en estudiantes con discapacidades o talentos excepcionales. Los resultados muestran que el nuevo perfil del docente inclusivo considera las variables de formación y competencias y los enfoques disciplinares pedagógicos-didácticos, psicopedagógicos, neuropsicopedagógicos y de la psiquiatría para el aprendizaje. Se concluye que el docente inclusivo transforma el proceso formativo mediante el conocimiento aplicado en situaciones propias, acompañado de habilidades humanísticas y de convivencia. Esto garantiza la ubicación de estudiantes con y sin discapacidad en aulas regulares de clases, sin inferir su rendimiento académico y generando beneficios sociales en la totalidad de los estudiantes.
\end{abstract}

\section{Profiling inclusive primary school teachers: with focus on transforming teacher-training processes at public educational institutions in the district of Cartagena, Colombia}

\begin{abstract}
The main objective of this study is to profile inclusive primary school teachers at educational institutions in the District of Cartagena, Colombia. The sample consists of 91 teachers from six public primary schools. This is a mixed design study supported by both quantitative and qualitative approaches. An ad hoc questionnaire is used to survey teachers and an orientation questionnaire guide is used to survey focus groups of teachers and professionals that support students with disabilities or with exceptional talents. The results show that the new profile of inclusive teachers includes training and competency variables and the following disciplinary learning approaches: pedagogical-didactic, psych-pedagogical, neuro-psych pedagogical, and psychiatry. It is concluded that inclusive teachers transform training processes through knowledge applied to particular situations with their students, which is accompanied by humanistic and coexistence skills. This guarantees the placement of students with and without disabilities in a regular classroom, without inferring their academic performances, and guarantees the generation of social benefits for all students.
\end{abstract}




\section{INTRODUCCIÓN}

El Ministerio de Educación y formación profesoral del Gobierno Español definió el concepto de Necesidades Específicas de Apoyo Educativo Diferenciado (NEAED) involucrando una serie de condiciones, identificadas hoy como necesidades educativas especiales, condiciones excepcionales, vinculación al sistema educativo con extra-edad, dificultades en el aprendizaje y situaciones personales que inciden en su desarrollo individual. De igual forma, el Ministerio de Educación Nacional de Colombia (MEN), a través de la normatividad educativa inclusiva y en especial con el Decreto 1421 del 2017, relaciona de manera intencional un conjunto de discapacidades, capacidades y condiciones excepcionales que pueden estar presente en un aula regular de clases, de manera que la totalidad de niños, niñas y jóvenes reciban una educación de calidad, con equidad y cobertura, aprendiendo juntos sin distinción alguna, implicando que la enseñanza se adapte a los estudiantes y no estos a la enseñanza, dando origen y de manera sancionatoria en el país a la Educación Inclusiva

Un perfil docente basado en las variables formación y competencias permitirá realizar transformaciones en el contexto educativo, favoreciendo su desempeño profesional, intelectual y su relacionamiento con la comunidad educativa (González et al., 2019). En ese sentido, las competencias profesionales docentes responden a unas funciones consideradas esenciales, diferenciando el ejercicio del maestro de otros profesionales que intervienen en el mismo contexto de trabajo. Los hallazgos obtenidos en los estudios realizados por Villarreal et al. (2019) permiten reconocer lo que las TIC han provocado a nivel de transformaciones en diversos sectores de la sociedad, entre estos el educativo. Las herramientas tecnológicas han facilitado la comunicación y a su vez, la comprensión de los numerosos contenidos que se imparten en la formación académica colocando a los docentes en el reto de adquirir las competencias y habilidades necesarias para poder implementarlas con éxito y que estas se conviertan en una verdadera fuente de progreso para la totalidad de los estudiantes, dada la conexión que generan las tecnologías en los estudiantes con discapacidad, trastorno o condiciones excepcionales. En este sentido, los autores consideraron importante emplear modelos probados y reconocidos para la gestión de las competencias digitales docentes, el uso de políticas educativas emanadas por parte del Estado que impactan en los centros educativos y contando con los elementos necesarios para llevarlos a cabo en y durante el desarrollo del acto educativo. Se debe promover en los docentes mayor compromiso con la renovación del conocimiento y la información, así como estimular la creación de contenidos digitales que fomenten las competencias en la totalidad del estudiantado (Villarreal et al., 2019).

De igual manera, Majoko (2019) determinó que la evaluación, la diferenciación de la instrucción, el aula, la gestión del comportamiento y la colaboración en el proceso educativo están relacionadas con competencias claves requeridas en los docentes de la educación inclusiva, debiendo estas habilidades estar al servicio de los profesores como recursos claves que facilitan la implementación exitosa y efectiva de una educación de todos para todos, donde las instituciones educativas deben dar el apoyo necesario para responder cabalmente a la diversidad de los estudiantes en los diferentes estadios de la vida. De forma complementaria, el autor hace referencia a la diferenciación entre niños(as) con discapacidades educativas y aquellos(as) que requieren instrucción intensiva o instrucción diferenciada, lo cual requiere formación docente, y las instituciones educativas deben equipar maestros en servicio con competencias para responder a la diversidad humana en el interactuar diario de aulas regulares (Majoko, 2019).

En Colombia, en el año 2006, con vigencia actual, desde sus lineamientos institucionales en el programa de formación de formadores, el Ministerio de Educación Nacional ha definido dos niveles de competencias, referenciadas como competencias genéricas y competencias específicas. Estas dos competencias se materializan con las denominadas competencias profesionales, las cuales debe tener el profesional de la educación en el desarrollo de su práctica y praxis pedagógica. Por su parte, la Secretaría de Educación Distrital (SED) de Cartagena, acogiendo lo decretado en la política educativa inclusiva del país, ha promovido una educación de todos para todos, tanto en instituciones educativas oficiales como en centros educativos privados. Las instituciones educativas oficiales del Distrito de Cartagena con potencial de escuelas inclusivas desde el año 2010 han estado admitiendo estudiantes con discapacidades y condiciones excepcionales como reza en la política educativa del país. Igualmente, algunos centros educativos o colegios privados vienen apoyando la educación inclusiva con el ingreso de estudiantes con discapacidad mental psicosocial y cognitiva, entre otras discapacidades, contando, además, con docentes formados y competentes que atienden estudiantes en escuelas oficiales que vienen apoyando en forma significativa la población en condición de discapacidad auditiva, ceguera y sorda ceguera.

Así, con el conocimiento de que las aulas inclusivas son una necesidad en los centros escolares del país, dando cumplimiento a la normatividad de una política educativa inclusiva, los entes territoriales, entre ellos el correspondiente al Distrito de Cartagena de Indias, ha contratado profesores especializados en discapacidades tanto físicas como cognitivas, además de capacitarlos y formarlos para su desempeño. A 
pesar de lo anterior, la incidencia de los procesos formativos ha sido mínima, debido a que se han dado en un número reducido de profesores, donde la gran mayoría todavía sigue desarrollando prácticas excluyentes. Los directivos docentes de los 6 centros de educación de la muestra representativa manifiestan que la formación docente se hace con el apoyo del ente territorial, considerando la disponibilidad presupuestal. La consolidación de las necesidades de formación profesoral hacen referencia a estrategias de aulas, especialmente las que se puedan apoyar con TIC, fortalecimiento de las competencias de creatividad e innovación haciendo las adaptaciones requeridas en especial para estudiantes en condición de discapacidad, adaptación de planes individuales de ajustes razonables, capacitación sobre estrategias de aprendizaje y atención a actuaciones conductuales que requieren intervención para manejar una convivencia sana y lograr el desarrollo integral de la totalidad de los estudiantes. Igualmente precisaron que por razones presupuestales el impacto de los procesos de cualificación docente solo alcanza a un número determinado. Así como también consideraron la necesidad de desarrollar habilidades en prácticas innovadoras inclusivas como una manera de dejar atrás las prácticas con metodologías excluyentes.

Ante esta realidad, la formación y el desarrollo de las competencias de los profesores juegan un papel importante en los logros de alcanzar una formación integral para la totalidad de los estudiantes. Durante muchos años, la enseñanza ha sido influenciada por teóricos reconocidos, quienes han investigado los diferentes métodos que utilizan los estudiantes para conceptualizar ideas y han demostrado que los individuos no aprenden de la misma manera, ni en el mismo ritmo, así como tampoco tienen las mismas necesidades educativas, obligando en los tiempos actuales a modificar las prácticas de enseñanza, el plan de estudio fijo y las formas de evaluación, generando cambios significativos que le permiten proponer un nuevo perfil de docentes de la educación inclusiva.

De tal modo, los fundamentos teóricos de la temática investigada están relacionados con la formación del docente de la educación inclusiva y las competencias derivadas de la formación; variables que definen, en este caso, el perfil del docente que apoya la inclusión, logrando transformar su práctica pedagógica para el aprendizaje de todos los estudiantes. Todos estos factores que de forma teórica influyen positivamente en el perfil del docente de la educación inclusiva permiten dar respuesta al interrogante sobre cuál es la formación y competencias del docente de las instituciones educativas oficiales del Distrito de Cartagena -Colombia, para atender desde las diferencias la totalidad de los estudiantes. Por ende, conocer la formación y competencias profesionales de los docentes de la muestra representativa es un punto de partida para elaborar una propuesta de diseño del perfil del nuevo docente de básica primaria, reconociendo las necesidades de cualificación para atender población estudiantil que demanda sus servicios y las competencias para el mejoramiento del proceso educativo.

\section{OTROS ANTECEDENTES}

La formación del docente para la inclusión educativa involucra el componente pedagógico como fundamento teórico del proceso y un componente didáctico como guía práctica, así lo manifiestan Florian l. y Linklater H. (2010) al considerar que se deben fomentar espacios para que los docentes evidencien como sus estudiantes aprendieron mediante el uso de estrategias trabajadas en forma colaborativa con colegas comprometidos con su labor. Considerando que se forma para ser competente, Florián y Black-Hawkins (2011) ponen de manifiesto que el conocimiento de la práctica inclusiva de los docentes, relacionado con lo que hacen, por qué lo hacen y cómo lo hacen permite articular el saber especializado y la habilidad requerida para enseñarle a la totalidad de los estudiantes, identificándolo a través de sus individualidades, pero haciendo el acto educativo para todos, en lugar de proporcionar diferencias entre todos y para algunos. La educación inclusiva fundamenta su desarrollo en la labor de los docentes, considerándolos elementos claves en el proceso de enseñanza y aprendizaje, por tal razón el paso de un modelo segregado a un modelo inclusivo exige docentes con actitudes positivas en el trato de los estudiantes con necesidades educativas específicas, En este sentido, De Boer et al. (2011), reconoce de igual forma la importancia del docente para lograr una asertiva comunicación con sus estudiantes y apoyar significativamente sus logros, concluyendo en sus estudios que la gran mayoría de los docentes tienen actitudes negativas o neutras en el trato con estudiantes de básica primaria que tienen alguna discapacidad o condición excepcional, encontrando variables asociadas al comportamiento de los docentes tales como su falta de formación y limitadas habilidades en la interacción con los estudiantes en el marco de su diferencia.

Específicamente, el desempeño profesoral inclusivo, según Fernández (2013), necesita un nuevo perfil de profesor, que permita atender estudiantes con diferentes estilos y ritmos de aprendizaje, así como con necesidades específicas que requieran apoyo educativo diferenciado. La docencia basada en el aprendizaje de los estudiantes amerita estar pendientes de cada uno, supervisar su proceso, facilitar su progreso mediante las ayudas didácticas, cuyo dominio evidencia que se tienen profesionales de la enseñanza con un proceso particular (Fernández, 2013). De hecho, Medina et al. (2013) en su libro "Formación del profesorado Actividades innovadoras para el dominio de las competencias docentes", aseveraron que el desarrollo de la 
competencia en el docente requiere consolidar las dimensiones que la integren aplicando con acierto los valores que constituyen las bases de los saberes, de forma que faciliten la solución de situaciones problemáticas relacionadas con su parte personal y profesional. Por otro lado, Conejeros et al. (2013) apuntaron a la necesidad de dinamismo de los estudiantes talentosos presentes en un aula, y dieron luces sobre la diversidad existente en condiciones excepcionales. En este aspecto, la diversidad se encuentra en la manifestación del talento, caracterizada por la inconformidad de los estudiantes talentosos cuando las clases se vuelven monótonas. En ese mismo sentido, los autores relacionaron las competencias docentes para atender estudiantes talentosos y el uso de recursos personales, precisando al respecto sobre el conocimiento de las características de los estudiantes con altas capacidades y el aprendizaje, al requerir un "buen manejo didáctico y de estrategias que estimulen las habilidades de pensamiento superior (pensamiento crítico, creatividad, resolución de problemas) y una actitud de apertura, de madurez y disposición para acompañar a los estudiantes en el desarrollo de su potencial" (Conejeros et al., 2013, p. 406).

Es de señalar que la implementación de la educación inclusiva trae consigo, en concordancia con Kurniawati et al. (2014), retos y desafíos para los docentes en aula en el momento que tienen que satisfacer las necesidades de aprendizaje de los estudiantes con y sin necesidades educativas especiales, las cuales según estos autores se necesita formación idónea, con contenidos y duración necesarios, de manera que el docente esté en condiciones de hacer los ajustes teniendo en cuenta los requerimientos de aprendizaje de la totalidad de los estudiantes. Las investigaciones indicaron que las cualificaciones se centraron en la actitud, conocimiento y habilidades de los profesores a corto plazo, complementadas con experiencias de campo.

Los problemas de educación de los docentes ocupan un lugar destacado en la agenda política en toda Europa, argumentándose que la educación inclusiva no solo proporciona el mejor ambiente educativo para los estudiantes con discapacidades, sino que también ayuda a romper barreras y desafiar los estereotipos. Autores mucho más recientes con posturas complementarias dieron sus aportes a la educación relacionados con el concepto de las aulas inclusivas. Muñoz et al. (2015) expresaron que los docentes tienen dificultades al "disponer de un lenguaje inclusivo para referirse a sus estudiantes, porque se ven obligados a utilizar las etiquetas aun cuando se destaquen las habilidades, capacidades y potencialidades de estos" (p. 77), sumado a la presión por responder a pruebas de Estado estandarizadas, lo que termina obstaculizando el respeto por los ritmos de aprendizaje, el hacer ajustes curriculares y planificar diferentes metodologías para un contenido (Muñoz et al., 2015).

Las prácticas desarrolladas por los docentes pueden promover u obstaculizar la inclusión en las escuelas, según el estudio desarrollado por Adderley et al. (2015), el concepto de inclusión o exclusión no está relacionado con lo que ocurre en el salón de clases sino a lo que ocurre durante el día en la escuela. Se reconoce la importancia del rol del docente y dentro de este las relaciones que desarrolle con los estudiantes, con el fin de lograr estados en los niños (as) de felicidad, evitando el aislamiento de estos y minimizando los espacios de exclusión que se puedan presentar.

La inclusión académica se ha convertido en los tiempos actuales en el mecanismo que asegura que los estudiantes en situación de discapacidad tengan iguales posibilidad de acceder a la educación como derecho fundamental de la humanidad, disponiendo de todos los recursos en una institución educativa para desarrollar su aprendizaje, sin ninguna discriminación (Fernández y Duarte, 2016). Desde este marco referencial, los autores evidencian la importancia del compromiso institucional con el cumplimiento de la normatividad inclusiva emitida por los gobiernos, relacionada con la inclusión de personas en situación de discapacidad en el contexto educativo; de esa manera, se reconoce la importancia de la capacitación de los docentes en el manejo de estudiantes con Necesidades Educativas Especiales (NEE), así como el conocimiento de la comunidad académica respecto a los derechos y posibilidades de acceso y permanencia en la institución de personas en situación de discapacidad (Fernández y Duarte, 2016). Actualmente, los centros educativos han entendido la importancia de establecer una política clara que favorezca la inclusión, que contemple planes y programas con estrategias pedagógicas orientadas a la atención de las NEE y en especial la capacitación docente en el uso de adaptación y flexibilidad curricular que tributen favorablemente en la formación integral de los estudiantes con discapacidad, implementando estrategias de comunicación y sensibilización que permitan la formación o el fortalecimiento de una cultura institucional inclusiva para el desarrollo de la población con discapacidad, sin discriminación alguna.

Hoy en día los maestros cuentan con amplias oportunidades para acceder libremente a una gran cantidad de Recursos Educativos Abiertos (REA), donde se espera que puedan seleccionar y transformar y / o aumentar para satisfacer las diversas necesidades de sus estudiantes y con estos ofrecer experiencias de aprendizaje inclusivas. Ante este gran reto de los sistemas educativos de hoy en día, los docentes son reconocidos como actores claves de apoyo a los procesos inclusivos y de la evaluación de los aprendizajes de las lecciones aprendidas a través herramientas técnicas, consistentes en recursos educativos accesibles basados en la web y otros, así como para lograr mejores resultados de aprendizaje de los estudiantes (Baldiris et al., 2016). 
Paniagua (2016) reflexionó sobre las inteligencias del ser humano, resaltó la inteligencia ejecutiva como un nuevo modo de ver la inteligencia humana, pues se consideraba que el aprendizaje era solo cognitivo y emocional; hoy la educación no consiste solo en aprender y conocer más, sino también dirigir el comportamiento hacia las metas elegidas. En este sentido se menciona que las competencias del docente de la educación inclusiva se relacionan en su práctica con actitudes del profesorado en la inclusión, prácticas inclusivas e interculturales, trabajo docente con proyectos, experiencias pedagógicas - didácticas, psicopedagógicas y neuro psicopedagógicas, con el propósito de lograr el manejo de conductas disruptivas y las habilidades comunicacionales con el profesorado. Desde su experiencia, el docente puede dar los primeros auxilios por así considerarlo, ante posibles situaciones que puedan redundar en problemas mayores, como afectación en el aprendizaje e incidencia en la conducta del grupo escolar.

Por otra parte, el incumplimiento de normas y la agresividad tanto verbal como física son síntomas que se pueden asociar a trastornos de conducta en los niños, niñas o jóvenes, considerando que tanto en la detección como en el apoyo es necesario conversar con los docentes y recoger de estos toda la información que pueda proporcionar. Las conductas disruptivas en el aula de clases son un fenómeno cada vez más habitual, tomando en cuenta que las medidas ordinarias de atención a la diversidad deben ser agotadas antes de recurrir a medidas extraordinarias y de igual manera, se cree que las conductas disruptivas por sí solas no brindan suficientes motivos sobre los cuales se decida la forma de escolaridad (Álvarez et al., 2016).

La formación del docente tiene que ver con su cualificación para el desarrollo de competencias, de modo que trabaje juntamente con el propósito de incentivar la participación y el aprendizaje de todos los estudiantes y conseguir desde este enfoque el mejoramiento de los establecimientos educativos. Jiménez et al. (2017) resaltaron el hecho de que cada día los grupos minoritarios, que se caracterizan por las desigualdades, generan desarrollo de propuestas basadas en principios de inclusión, multiculturalidad y diversidad. Así pues, cuando los sistemas educativos permiten involucrar contenidos curriculares a diferentes culturas, se privilegian las interacciones colaborativas y se ajustan las ayudas a las necesidades de los estudiantes. De igual forma, el Decreto 1421 de 2017, sancionado por la Presidencia de la República de Colombia a través del Ministerio de Educación Nacional, involucra docentes formados y con competencias para desarrollar su práctica y praxis pedagógica en el marco de las diferencias individuales de los estudiantes, apoyados por profesionales del equipo psicosocial para interactuar en escenarios como el aula, espacios de prácticas, trabajo de campo u cualquier otro, con el fin de lograr competencias comunicativas, situación que a la fecha requiere ser fortalecida, en razón a que los rasgos de personalidad en la gran mayoría de las veces son afectados por la condición de discapacidad o condiciones excepcionales.

El sistema educativo colombiano permite que además de los licenciados en educación, los profesionales de otras disciplinas puedan desarrollar la labor docente mediante cualificación pertinente como profesionales no licenciados, y ante esta realidad en los resultados de procesos investigativos desarrollados por Rodríguez e Hinojo (2017), se evidencia la necesidad de implementar acciones de mejora como la ampliación del tiempo para el desarrollo de procesos formativos en pedagogía, así como la reestructuración de la evaluación y la posible homologación de créditos del programa para estudios de postgrado, lo anterior tendiente a contribuir significativamente en la cualificación del perfil del educador no licenciado. Aunado a ello, consideraron que cuando se presentan dificultades académicas en la cualificación en pedagogía del profesional no licenciado, las tutorías extracurriculares son una herramienta que favorece el proceso.

Los docentes en formación, conocidos en diferentes contextos como en pre-servicio, requieren apoyo de sus maestros mentores y supervisores universitarios para reflexionar sobre sus éxitos y retos en el avance de las prácticas inclusivas profesionales y en este sentido, las escuelas deben trabajar a través de sus docentes en ejercicios sobre adaptaciones curriculares para atender estudiantes con discapacidades, estando preparados para entablar conversaciones y tener discusiones significativas sobre los beneficios, estrategias y mejores prácticas necesarias en la educación inclusiva (Zagona et al., 2017). El liderazgo inclusivo de los directivos de los centros escolares influye positivamente en la práctica del profesorado, lo anterior es necesario considerarlo teniendo en cuenta que, en el contexto colombiano, el Ministerio de Educación Nacional (MEN) considera a directivos y coordinadores como directivos docentes.

El tránsito de un modelo terapéutico e integrador a un modelo de educación inclusiva exige docentes con funciones y actuaciones diferentes, así como docentes de apoyo que garanticen un proceso de aprendizaje con resultados favorables para la totalidad de los estudiantes, en especial para los niños(as) con necesidades educativas especiales. El docente que apoya la inclusión, según Soldevila et al. (2017), desde su práctica docente ha hecho posible una mayor presencia, participación y progreso de estudiantes con diversidad funcional en un aula regular, favoreciendo su desarrollo social, emocional y académico. En este sentido, los autores anteriores consideran que tanto el docente y el profesional pedagógico que apoya al proceso, deben desarrollar el acto educativo considerando su papel en la transición del modelo integrado a uno inclusivo como 
un cambio conceptual que necesariamente modifica tanto el rol del profesor como del profesional pedagógico de apoyo, de igual forma deben crear entornos de aprendizaje y no solo limitarse a transmitir conocimientos, tareas que realiza el profesor.

La educación inclusiva en los tiempos de hoy se desarrolla en el marco de modelos inclusivos, permitiendo el ingreso de estudiantes con discapacidades y condiciones excepcionales, entre otras condiciones de vulnerabilidad, donde las expectativas tanto del estudiante como del docente son más altas. En este escenario se identifica un docente de educación general y un equipo psicosocial, donde ambos se deben enfrentar y apoyar las barreras potenciales de los estudiantes, para lograr con los ajustes curriculares y las habilidades de colaboración el éxito del proceso educativo (Da Fonte et al., 2017). La inclusión de estudiantes con discapacidades se ha venido practicado en el territorio nacional colombiano y ha implicado en los casos dados la colocación de estudiantes con discapacidades en un aula de clases, con un instructor principal, quien es un docente de educación general que se apoya en un equipo psicosocial (psicólogo educativo, psicopedagogo, trabajador social, fonodiologo), donde los programas de formación de docentes en preservicio están considerando lo requerido en el contexto educativo para desarrollar con éxito la práctica docente y así cumplir las necesidades de la totalidad de los estudiantes, a fin de proporcionar a los futuros docentes de educación primaria, un buen conocimiento y una práctica relacionada con la comprensión de la discapacidad con instrucción diferenciadora.

En el trastorno disocial escolar, el cual está relacionado con la discapacidad mental psicosocial, según Gómez (2018) el modelo acción docente es considerado una alternativa pedagógica que favorece el manejo en el contexto escolar, especialmente en el aula de clases. En la definición de su modelo de acción, Gómez (2018), considera que para apoyar el desempeño docente y prevenir los comportamientos relacionados con la violencia, la agresividad y el incumplimiento de normas de convivencia es importante que este sea formado desde experiencias y procedimientos vivenciales de manera que logre las habilidades para el manejo asertivo de estas conductas, lográndose un impacto en el fortalecimiento de las competencias en los profesores para prevenir situaciones futuras relacionadas con el trastorno disocial escolar. Las técnicas de la inteligencia artificial, están asociadas al trabajo investigativo desarrollado por Álvarez, Salazar y Ovalle (2018) como recursos educativos tecnológicos que permiten solventar problemáticas que aún persisten en el aprendizaje colaborativo asociadas a fallas cognitivas en los entornos de aprendizaje, donde la incorporación de las actividades al proceso de enseñanza le exige al docente el fortalecimiento de sus competencias tecnológicas mediante el uso de metodologías asociadas.

La intervención y seguimiento de patologías relacionadas con la condición de discapacidad mental psicosocial, referidas al Asperger y al Trastorno de déficit de atención e hiperactividad (TDAH) apoyadas en plataformas computacionales, basados en textos, permiten interacciones sociales y potencializan el desarrollo cognitivo de estos, en especial cuando se realizan en forma temprana al convertirse en una ventaja en la toma de decisiones en pro del desarrollo de la persona en condición de discapacidad, así lo consideran Arroyabe et al. (2018). Además, concluyen que se convierten en una fuente de información importante para los terapeutas, especialistas, familiares y docentes, que pueden ser utilizadas durante el proceso de atención del estudiante. Lo anterior fue corroborado por Besantes et al (2018) en su estudio relacionado con el uso de recursos tecnológicos consistentes en lectores de pantalla con el fin de fortalecer el aprendizaje de las personas no videntes, lo que facilita la interacción entre ellos, con los docentes y con los contenidos virtuales, convirtiéndose en una aliada para la construcción y el desarrollo de la equidad e inclusión de grupos vulnerables a la educación regular, fortaleciendo la autoestima de estudiante al lograr la compensación de sus limitaciones funcionales y de igual forma el fortalecimiento de las competencias docentes incidiendo significativamente en su perfil profesional (Basantes et al, 2018).

Los saberes y la práctica profesional, a través de sus experiencias pedagógicas, posibilitan la creación y el desarrollo de una relación educativa que atienda a las necesidades individuales y a las particularidades de sus alumnos, por medio del apoyo, de lo que se vive en el aula de clases (Orozco y Moriña, 2019). Otro aporte reciente fue realizado por Alegre y Villar (2019), en su estudio sobre problemas emocionales y desarrollo del lenguaje en población con discapacidad auditiva, en cuanto al reconocimiento de la importancia de análisis de "las aptitudes psicolingüísticas de niños y adolescentes e investigar los problemas emocionales de niños y adolescentes como predictores de sus aptitudes comunicativas y de lenguaje" (Alegre y Villar, 2019, p. 6), lo que permite proponer programas educativos con base en aptitudes psicolingüísticas, cursos de formación para padres y talleres de desarrollo profesional docente de educación inclusiva para estudiantes con estas dificultades, con el propósito de desarrollar competencias en los docentes. Por su parte, Domínguez et al. (2016) citados por Alegre y Villar (2019) sugirieron programas psicoeducativos para el desarrollo emocional y las habilidades sintácticas, de lectura, vocabulario y estrategias semánticas para niños y adolescentes, los cuales deben incluir estrategias "implantadas por maestros especialistas en audición y lenguaje que participan con los maestros tutores en la mejora de problemas de conducta y de comprensión del significado de materiales curriculares presentados oralmente en la enseñanza" (p. 21). 
En su estudio, la Enseñanza colaborativa, relacionada con la exploración del impacto de la prácticas de coenseñanza en el logro de conocimientos de aritmética de estudiantes con y sin necesidades específicas que requieren apoyo educativo diferenciado, Lehane y Senior (2019) ponen de manifiesto que los especialistas en educación señalan como pertinente el uso de enfoques de enseñanza de apoyo mutuo en el trabajo con estudiantes que requieren adaptaciones curriculares y ajustes individuales en sus procesos de aprendizaje, al calificarlas como una forma eficaz de intervenciones académicas. Desde el enfoque de la educación inclusiva, los profesores que lideran el proceso académico de estudiantes con alguna discapacidad en clases regulares vienen dando apoyo y educación física adaptada a sus necesidades, a pesar de lo anterior, ante ciertas circunstancias y situaciones propias de la condición no se sienten lo suficientemente preparados y seguros del apoyo dado (Hutzler et al., 2019). Las investigaciones realizadas por Hutzler et al. (2019) ponen de manifiesto la necesidad de un modelo que incluya como variables los antecedentes del docente, el respecto a sus atributos personales, así como los atributos del centro escolar, los atributos de la discapacidad en particular y por último el comportamiento de los docentes ante la inclusión. En el sentido práctico, los autores anteriores, consideran que los profesionales de la inclusión deben ser conscientes de factores como la experiencia cuantificada de docentes de personas con discapacidad, en el contexto escolar, familiar y social y la formación profesional del docente en el tema de la inclusión. Adicionalmente, consideran factores individuales como el género del discapacitado, factores ambientales de la escuela que facilite el desempeño, así como también el tipo y grado de discapacidad.

La condición síndrome de Down, en el marco de la discapacidad cognitiva, se ha venido trabajando en el contexto escolar desde unas posturas subjetivas, que, a la luz de las experiencias, los resultados objetivos y los retos de la educación del siglo XXI deben ser revaluadas. En este sentido, Bonilla et al. (2020) hacen referencia a las creencias referidas a la percepción del síndrome de Down, el apoyo laboral recibido, las estrategias pedagógicas y dificultades percibidas, la inclusión escolar y la visión del estudiante. Los estudios del grupo destacan teorías subjetivas relacionadas a las dificultades atribuidas a los alumnos con síndrome de Down que fueron modificadas y evidenciadas especialmente en lo relacionado al uso de estrategias pedagógicas que permitieron impulsar su creatividad y kinestesia mediante el uso de un mismo lenguaje. La autonomía escolar y la inclusión educativa se vienen uniendo como una estrategia con efectos positivos en estudiantes con necesidades educativas especiales, así lo consideran Liua et al. (2020) en sus resultados de investigaciones donde la autonomía está relacionada con la composición socioeconómica de los centros escolares, donde las escuelas que tienen apoyos de patrocinadores resultaron con un nivel de autonomía alto, minimizando con esto el índice de estudiantes que requieren apoyo educativo adicional por parte del profesorado y de estudiantes con necesidades educativas especiales.

\section{NORMATIVIDAD COLOMBIANA}

La normatividad inclusiva en Colombia incluye una serie de leyes, decretos, resoluciones y circulares sancionadas por el Gobierno Nacional, las que en materia educativa les correspondió al MEN. El país como tal ha definido un modelo de inclusión compuesto de un conjunto de aristas, identificadas y relacionadas con grupos poblacionales vulnerables, tales como la población con discapacidad, capacidades y condiciones excepcionales, población étnica, poblaciones habitantes de frontera, población afectada por los grupos al margen de la ley y la población vulnerable por género y rol sexual como sujeto. En este sentido el MEN, considerando la arista del modelo relacionado con la condición de discapacidad, capacidad y condiciones excepcionales derogó el Decreto 1421 del 29 agosto de 2017, desde el cual se le da responsabilidad a los centros escolares para atender desde el esquema de una educación de todos para todos a la totalidad de la población que soliciten el servicio educativo como un derecho universal.

Sobre lo descrito con anterioridad es relevante el hecho de que el país ha pasado de una educación segregada, desarrollada a través de centros escolares reglares y centros escolares especiales, a una educación inclusiva donde estudiantes con estilos y ritmos de aprendizajes, así como con necesidades específicas que requieren apoyo educativo diferenciado, pueden recibir su formación en una misma aula regular de clases. Situación que se fundamenta como se dijo anteriormente con el sancionado decreto 1421 de 2017. En el marco de la educación segregada, el gobierno sancionó la Resolución 2565 de octubre 2003, durante el cual se impulsaron las aulas de apoyo y algunas instituciones educativas del país y entre ellas 15 centros escolares del Distrito de Cartagena de Indias - Colombia, se acogieron a esta normatividad y recibieron apoyo en la capacitación de docentes, ejercicios de flexibilidad curricular y dotación de recursos educativos para atender determinadas condiciones de discapacidad, lo que les originó alguna especialidad en las condiciones de discapacidad auditiva, visual y cognitiva. Lo anterior se considera un buen inicio para lograr el trabajo de centros escolares donde puedan recibir formación estudiante en condición de discapacidad, capacidades y/o talentos excepcionales, estos últimos identificados como talentosos o superdotados. Ante el mandato de gobierno, la totalidad de los centros escolares deben ser inclusivo, 
contándose con un plazo de 5 años a partir del 29 de agosto de 2017 para lograr las bases y experiencias de poder atender la totalidad de los estudiantes sin distinción alguna.

\section{METODOLOGÍA}

El estudio desarrollado es de tipo descriptivo con enfoque mixto, debido a que se hace un análisis utilizando datos tanto cuantitativos como cualitativos. La naturaleza del estudio permite desarrollar un análisis de tipo cuantitativo mediante la aplicación de un instrumento para evaluar la formación y competencias de los docentes, desde la pedagogía y didáctica inclusiva que les permita atender las necesidades específicas de los estudiantes que requieren apoyo educativo diferenciado y un análisis de tipo cualitativo (a través de opiniones de los grupos focales), para evaluar la aplicación práctica de las capacidades y competencias de los docentes.

El objetivo general consistió en diseñar el perfil de formación y competencias del nuevo docente inclusivo de básica primaria en el proceso formativo desarrollado en las instituciones educativas oficiales (IEO) del Distrito de Cartagena de Indias - Colombia, de manera que pueda atender desde la diversidad y haciendo uso de la pedagogía y didáctica inclusiva las necesidades específicas de los estudiantes que requieren apoyo educativo diferenciado. Se definieron como objetivos específicos, describir la formación y competencias para atender desde la pedagogía y didáctica inclusiva las necesidades específicas de los estudiantes de básica primaria que requieren apoyo educativo diferenciado; sistematizar los aportes de los docentes, psicólogos educativos y de los profesionales especialistas de apoyo en los procesos de diagnóstico, tratamiento e intervención pedagógica de los estudiantes con discapacidad o condiciones excepcionales, sobre la formación y competencias del docente de educación inclusiva, y determinar el nuevo perfil del docente desde las variables formación y competencias que permitan atender el proceso formativo en el desempeño de las prácticas educativas inclusivas.

Las instituciones educativas oficiales potencialmente inclusivas del Distrito de Cartagena son 15 definidas por la Secretaría de Educación Distrital (SED), de las cuales seis hacen parte del estudio, en las que sus rectores se mostraron altamente interesados en participar y porque han venido fortaleciendo sus procesos en el tema de flexibilidad curricular, formación de profesores y dotación de recursos didácticos que apoyan la inclusión. Adicional a ello, han admitido durante estos últimos años población con diferentes discapacidades y condiciones excepcionales. La población estudiantil de básica primaria con discapacidad y condiciones excepcionales fue de 1265 estudiantes en el año 2018 en la muestra de centros educativos. El total de 1265 estudiantes admitidos como diagnosticados en condición de discapacidad y condiciones excepcionales de los 6 centros educativos de la muestra corresponde al 4,5\% del total registrado como matricula en el año 2018 (28.105 estudiantes) en los 15 centros educativos declarados por el SED como escuelas potencialmente inclusivas y al $0,60 \%$ de la totalidad de la matricula registrada (214.547 estudiantes) en el año 2018 en los 111 centros educativos. Vale la pena resaltar que la matricula registrada en condición de discapacidad y condiciones excepcionales en el SIMAT (Sistema Integrado de Matrícula escolar) solo corresponde a los diagnosticados, encontrándose un número significativo de admitidos pendientes de engrosar las estadísticas a falta de un diagnóstico por los profesionales correspondientes, aunque presenten rasgos y dificultades en el aprendizaje. Sobre esta realidad le toca intervenir pedagógica y didácticamente al docente.

En las condiciones actuales, el modelo inclusivo del país no considera los centros de educación especial, en razón a que el decreto 1421 declara que la totalidad de los centros educativos deben recibir y apoyar la formación integral de la totalidad de sus estudiantes. De igual forma están en caso contrario las denominadas escuelas especiales existentes en el país, debiendo convertirse en inclusivas al recibir estudiantes regulares. El decreto hace referencia a un profesor formado para atender la inclusión en el acto educativo, con formación y competencias y un equipo psicosocial que apoya el proceso en los casos requeridos con acompañamiento fuera y dentro del aula.

La población docente de básica primaria en las 6 Instituciones Educativas Oficiales (IEO) fue de 120 en el año 2018, sin variación en número en el año 2019. En el 2020, según registros de la SED, en las 6 instituciones educativas referenciadas en el estudio la población fue de 113 docentes en básica primaria, generándose una disminución del 6\% en el 2020 con relación al año 2018. Aplicando la fórmula para el cálculo de muestra representativa en poblaciones finitas, con una confiabilidad del $95 \%$ y un margen de error del $5 \%$, la población a encuestar es de 91 profesores, constituidos por $94 \%$ mujeres y $6 \%$ hombres, con edades entre 27 y 60 años. La participación de docentes de género femenino fue mayor en los 6 centros de educación en comparación con los hombres que fue minoritaria. Las IEO de Bayunca y Olga González Arraut su planta de docente a nivel de básica primaria es 100\% femenina. La IE Ciudad de Tunta cuenta con 2 hombres de 17 en total en su planta profesoral de básica primaria. Por último, las instituciones educativas Antonia Santos, Arroyo de Piedra y República de El Líbano cuentan solo con un hombre en la planta de personal docente de básica 
primaria. La sistematización de la información obtenida a través del instrumento (encuesta) se hizo a través del paquete estadístico SPSS, Versión 22.0.

Los grupos focales estuvieron constituidos de la siguiente manera: Grupo 1. Docentes de básica primaria del distrito, psicólogos educativos y demás profesional del equipo psicosocial que intervienen en el proceso de formación de los estudiantes, organizados en 8 grupos de 11 participantes, de los cuales el $64 \%$ fueron docentes, seguidos del $30 \%$ psicólogos educativos y un $6 \%$ trabajadoras sociales. Grupo 2. Docentes de apoyo educativo de básica primaria, psicólogos clínicos, psicopedagogos, neuropsicólogos y psiquiatras con experiencia en atención de población escolarizada, que actualmente vienen apoyando el proceso de diagnóstico, tratamiento e intervención académica de los estudiantes, organizados en 6 grupos de 10 participantes, de los cuales el $38 \%$ fueron psicólogos clínicos, un $33 \%$ docentes especializados en NEE, 14 $\%$ psicopedagogos, $10 \%$ neuro psicopedagogos y un $5 \%$ psiquiatras con experiencia en atención a la población escolarizada en desarrollo. El criterio de selección de los integrantes del Grupo focal 1, fue su participación directa en el proceso formativo de los estudiantes, y de forma diferenciada, el criterio de selección de los integrantes del grupo focal 2, fue su participación en el proceso de diagnóstico, tratamiento e intervención académica de los estudiantes. Los docentes y psicólogos educativos de cada grupo focal pertenecen a las instituciones participantes en el estudio, más otros psicólogos educativos invitados de diferentes instituciones educativas del Distrito de Cartagena, que vienen apoyando protocolos de atención inclusiva. Los psicólogos clínicos, psicopedagogos, neuropsicólogos y psiquiatras con atención a población escolarizada del grupo focal 2 fueron invitados para conocer su opinión sobre los apoyos que pueden dar los docentes durante el acto educativo desde los enfoques disciplinares referenciados que vienen apoyando los diagnósticos, tratamiento e intervención en población escolarizada con discapacidad o condiciones excepcionales.

Las herramientas específicas de la investigación involucran un instrumento diagnóstico y una guía orientadora de preguntas a grupos focales. El instrumento de diagnóstico de formación y competencias docentes para atender estudiantes con necesidades específicas que requieren apoyo educativo diferenciado sirve para la recogida de información primaria, el cual consta de dos formularios: en uno se recogió la información de la formación del docente y la de dimensión Saber de competencias y en el segundo la información de dimensión Saber Hacer, Saber Ser y Saber Convivir de competencias. En el diseño y validación del instrumento se desarrollaron un conjunto de pasos que incluyen la definición del constructo o aspecto a medir, el propósito de la escala de medición y el proceso de validación.

La definición del constructo está relacionada con la reflexión de lo que queremos medir, a través de una revisión bibliográfica exhaustiva y la consulta a expertos en los temas de formación y competencias de los docentes para atender las necesidades específicas que requieren apoyo educativo diferenciado en un aula regular de clases regular. De esta manera se toma como referencia el concepto de formación y competencias docentes para la inclusión del alumnado de diferentes autores quienes han venido trabajando la necesidad de desarrollar clases inclusivas con docentes formados para la diferencia del estudiantado. Estas habilidades y destrezas están relacionadas con el componente pedagógico, didáctico, cultura y normatividad inclusiva, liderazgo, aprendizaje cooperativo, acompañados de competencias investigativas, interactivas comunicativas, éticas, consideradas necesarias a la hora de desarrollar prácticas inclusivas. El constructo definido va a medir en primera instancia la formación en pedagogía y didáctica de los docentes de básica primaria de las IEO del Distrito de Cartagena.

Seguido se miden las "competencias de los docentes para desde la pedagogía y didáctica inclusiva atender las necesidades específicas que requieren apoyo educativo diferenciado en las discapacidades, capacidades y talentos excepcionales presentes en las IEO inclusivas del Distrito de Cartagena- Colombia. Considerando lo expresado anteriormente, se hizo una revisión detallada de las posibles características que conforman dichas competencias, relacionadas con el concepto de competencias que se viene trabajando desde el Ministerio de Educación Nacional de Colombia, incluyendo las dimensiones de competencias. La definición de las dimensiones de competencias relacionadas con el proceso investigativo del SABER, se refieren a conocimientos sobre las discapacidades, capacidades y talentos excepcionales; el SABER HACER a conocimientos aplicados del Saber, el SABER SER a valores como empatía, solidaridad, equidad, comprensión, manejo ético y moral y el SABER CONVIVIR a valores como respeto a las diferencias.

En cuento a las preguntas específicas relacionadas con la formación inclusiva del docente y las dimensiones de competencias inclusivas fueron tomadas del instrumento diseñado del Trabajo Fin de Máster (TFM) en la UNED del presente autor para la condición Trastorno déficit de atención e hiperactividad (TDAH), debiendo ser ajustada a las demás discapacidades, capacidades y condiciones excepcionales definidas por el MEN. EI instrumento diseñado para el TFM en la UNED obtuvo su estado inicial de la tesis doctoral "Elaboración de un cuestionario para detectar el grado de conocimientos de docentes respecto al TDAH", de Pintor (2011). Como su nombre lo indica, referidas a los conocimientos que tienen los profesores sobre el TDAH. Las demás 
dimensiones de competencias fueron diseñadas ad hoc en un segundo momento siguiendo los lineamientos del instrumento anterior.

El formulario 1, con tres dimensiones, la primera relacionada con los datos sociodemográficos del encuestado, la segunda con la formación de profesores y la tercera con la dimensión Saber de competencias de los profesores. La dimensión de formación de profesores hace referencia a las áreas de pedagogía- didáctica y psicología educativa con un conjunto de preguntas dicotómicas, en escala de Sí/No. La dimensión de competencia Saber está compuesta por 84 ítems, sus preguntas tienen respuestas dicotómicas (Sí/No), relacionadas con los fundamentos básicos de las discapacidades y condiciones excepcionales, normatividad educativa, pedagogía- didáctica inclusiva y cultura institucional inclusiva. El formulario 2 compuesto por 56 ítems, con el que se recogió la información de las dimensiones de competencias del Saber Hacer, Saber Ser y Saber Convivir, las cuales constan de preguntas en escala tipo Likert, con cinco categorías, relacionadas con habilidades propias de estas dimensiones. Cabe aclarar que el ejercicio de aplicación del instrumento fue accedido a través de un enlace, asimismo, se les entregaron instrumentos en físico para aquellos docentes que manifestaron preferencia en diligenciarlo manualmente. En la validación estadística de los instrumentos se aplicó la prueba alfa de Cronbach, como modo más habitual para estimar la confiabilidad y validez de un instrumento, determinándose el grado en que el instrumento mide lo que se va a medir, reflejando confiabilidad dada a los datos. La prueba dio un resultado de $0,96 \%$, lo que indica que existe una elevada correlación entre los ítems y el puntaje total. En este proceso se aplicó el instrumento a cada profesor de básica primaria de las seis instituciones educativas oficiales de la muestra representativa, seleccionado mediante un muestreo simple sin reemplazamiento, cuya información fue registrada en un aplicativo del Formulario Google.

Para el desarrollo de los grupos focales se utilizó una guía orientadora de preguntas, validadas por un equipo de expertos en pedagogía y psicopedagogía con formación doctoral y experiencia en el campo, conformada por una pregunta general y varias preguntas orientadoras. Donde la pregunta general estuvo asociada a la categoría formación y ésta a las subcategorías "necesidades de cualificación" y a las "dificultades que ha tenido en el desarrollo de su práctica docente por desconocer los aportes de los nuevos enfoques disciplinares que vienen complementando los profesionales de apoyo y especializados". La categoría competencias fue asociada a las subcategorías "dimensiones de competencias" y a las "cualidades personales del docente". Las categorías formación y competencias estuvieron asociadas a los enfoques disciplinares de la pedagogía y didáctica a través del grupo focal $1, y$ a los enfoques disciplinares de la psicopedagogía, neuro psicopedagogía y psiquiatría para el aprendizaje a través del grupo focal 2, categorías que sirvieron de complemento para definir el nuevo perfil del docente inclusivo que les permita atender estudiantes en condición de discapacidad y condiciones excepcionales. A nivel de referentes conceptuales iniciales, se tuvo en cuenta la revisión de antecedentes de estudios sobre la temática estudiada, a nivel local, regional, nacional e internacional. Contando con el respaldo de la Secretaría de Educación Distrital de Cartagena, a nivel institucional y con la disposición de funcionarios de las seis instituciones inclusivas fue viable desarrollar el trabajo investigativo. El proceso de transcripción se realizó a partir de las preguntas validadas y aceptadas por los expertos. En cuanto al procedimiento de codificación e interpretación se realizó con la creación de la Unidad Hermenéutica en ATLAS. Ti. Unidad de contenido de todos los documentos que se incluyen en el análisis. Inicialmente se cargó el documento primario (entrevista) en formato PDF para su lectura en el programa. Seguidamente, se leyó todo el documento y se realizó la codificación teniendo en cuenta las categorías y subcategoría abordadas en el desarrollo del trabajo.

El proceso de diseño y desarrollo del proceso investigativo contempló tres etapas, donde la primera etapa consistió en la caracterización de la formación y competencias del docente para atender desde la pedagogía y didáctica inclusiva las necesidades específicas de los estudiantes de básica primaria de las IEO. La segunda etapa permitió conocer el contraste entre el acervo teórico existente sobre la formación y competencias del docente inclusivo con las obtenidas en la caracterización del docente en el contexto estudiado y la tercera, el diseño del nuevo perfil del docente que atienda el proceso educativo en el desempeño de las prácticas educativas inclusivas en el Distrito de Cartagena.

La primera etapa involucró actividades como el diseño y validación del instrumento diagnóstico de la formación y competencias del docente inclusivo, selección de las IEO con potencial de escuelas inclusivas, la formulación del Plan de investigación, la aplicación del instrumento validado para identificar la formación y competencias de los docentes para atender desde la pedagogía inclusiva estudiantes con discapacidades, capacidades y condiciones excepcionales, la construcción y aplicación de un formato de entrevista para explorar las concepciones de los directivos docentes y equipo psicosocial sobre las experiencias del docente en la relación con los estudiantes con necesidades específicas que requieren apoyo educativo diferenciado y por último en esta primera etapa, la elaboración de conclusiones y recomendaciones. En la segunda etapa del proceso investigativo, estuvo constituida por las actividades de elaboración de matriz que relacionó el acervo teórico y los resultados obtenidos, mediante el proceso de triangulación. 
La triangulación de los aportes desde el paradigma cuantitativo a través de la sistematización de las encuestas y del paradigma cualitativo a través de las voces de los participantes en los grupos focales permitió la definición del nuevo perfil del docente inclusivo. La tercera y última etapa contempló las actividades de definición de los elementos básicos del perfil general del docente inclusivo, la definición de los elementos básicos perfil específico para las IEO con potencial inclusivo del Distrito de Cartagena, el diseño del perfil del nuevo docente para las IEO con potencial inclusivo del Distrito de Cartagena y la elaboración del informe final de resultados del proyecto.

\section{RESULTADOS}

A continuación, se presentan los resultados obtenidos a través de los diferentes procesos de recogida de información y análisis de datos efectuados. Se agrupan, para mayor claridad en cinco subsecciones: Caracterización de la formación y las competencias del docente inclusivo, resumen estadístico descriptivo de las variables transformadas, sistematización de los aportes de los grupos focales, perfil del docente de la educación inclusiva, y perfil del nuevo docente de la educación inclusiva

\section{Caracterización de la formación y las competencias del docente inclusivo}

Considerando en el presente estudio las variables formación y competencias del docente inclusivo, se presentan por separado los resúmenes estadísticos de cada una de ellas. Relacionado a la formación del docente inclusivo, el 70,3\% de los docentes encuestados manifestaron haber recibido formación en las áreas de pedagogía y psicología educativa. A diferencia de un reducido número de profesores que representan el $29,7 \%$, quienes aseguraron no haber recibido formación alguna en estas áreas. El 48,4 \% de la muestra poblacional manifestó que la formación recibida fue obtenida a través de los programas de formación desarrollados por el ente territorial. Las escuelas regulares han estado atendiendo estudiantes con discapacidades y condiciones excepcionales, así como el ente territorial ha venido formando a los docentes del distrito en temáticas relacionadas con el propósito de generar un impacto positivo en su práctica y praxis pedagógica. En ese orden de ideas, el 40,6 \% aseguró haber recibido formación relacionada con las discapacidades y condiciones excepcionales, las cuales a la luz del Decreto 1421 de agosto de 2017 pueden estar presente en una escuela regular. A diferencia de un 59,4 \% que expresó no haber recibido ni tener conocimiento de los fundamentos básicos de estas discapacidades o condiciones excepcionales.

El carácter obligatorio de la educación en el país condiciona admitir y lograr mediante el tránsito de todos los estudiantes por la formación básica primaria y secundaria, las competencias que les permita aprender y permanecer en el sistema educativo hasta que logren obtener las respectivas titulaciones. En ese sentido, el decreto respalda la inclusión en el sistema educativo de 10 discapacidades, cuyos resultados evidencian una mayor proporción en formación recibida en la discapacidad intelectual $(27 \%)$, seguido de la sensorial auditiva y visual ( $23 \%$ y $21 \%$, respectivamente), donde teniendo en cuenta los índices alcanzados se debe cualificar a los docentes en estas y de igual forma, en las demás discapacidades que hoy en día, desde el enfoque inclusivo, pueden estar presente en un aula regular de clases. Cabe resaltar que la pedagogía contemporánea, con sus estudios recientes, considera que tanto los estudiantes que tienen discapacidad como los que tienen condiciones excepcionales requieren un acompañamiento especial con atención de consideraciones que les permita desarrollar su proceso educativo en condiciones de calidad, siendo imperativo que sean incluidos teniendo en cuenta sus individualidades. En este aspecto, los docentes ameritan ser formados para atender desde las diferencias a los estudiantes con condiciones excepcionales, debido a que el índice de formación en los diferentes talentos no supera en promedio el $6 \%$.

En cuanto a las habilidades o destrezas del docente en la educación inclusiva, inicialmente se determinaron los estadísticos de los interrogantes relacionados a las dimensiones de competencias del saber, saber hacer, saber ser y saber convivir. Los estadísticos relacionados a la dimensión del Saber cómo variables categóricas, a nivel de consolidado, constituida por los conocimientos sobre necesidades educativas especiales, normatividad inclusiva, pedagogía y didáctica inclusiva y cultura institucional inclusiva, arrojaron como resultados que el $81 \%$ posee esta dimensión de competencia a diferencia de un $19 \%$ que no la posee. Sobre las temáticas referenciadas la mayor proporción la obtuvo la cultura institucional inclusiva (84\%), seguida por la pedagogía-didáctica inclusiva (83\%). En menor proporción se ubicaron los conocimientos básicos sobre discapacidades, capacidades y condiciones excepcionales, y la normatividad inclusiva (79 \% y $78 \%$, respectivamente).

El consolidado de los ítems de la dimensión Saber Hacer de competencia determina que en un porcentaje del $82 \%$ los docentes son competentes, en la escala de Casi Siempre y un $12 \%$ en la escala de Siempre. Solo un $6 \%$ son competentes en la escala Ocasionalmente de la dimensión del Saber Hacer. El consolidado de los ítems de la dimensión Saber Ser de competencia determina que en un porcentaje el $65 \%$ los docentes son competentes, en la escala de Siempre y en un $13 \%$ en la escala de Casi Siempre. Solo un $5 \%$ son 
competentes en la escala Ocasionalmente en la dimensión del Saber Ser de competencias. El $72 \%$ fue valorado en Siempre según la escala en la dimensión Saber Convivir. Seguido de la opinión del $25 \%$ de los docentes, quienes manifiestan tenerla desarrollada en una frecuencia de Casi Siempre. Solo el 3 \% lo valoró en Ocasionalmente. El consolidado de las cuatro dimensiones (Saber, Saber hacer, Saber ser y Saber Convivir) de competencias se presenta en la Figura 1.

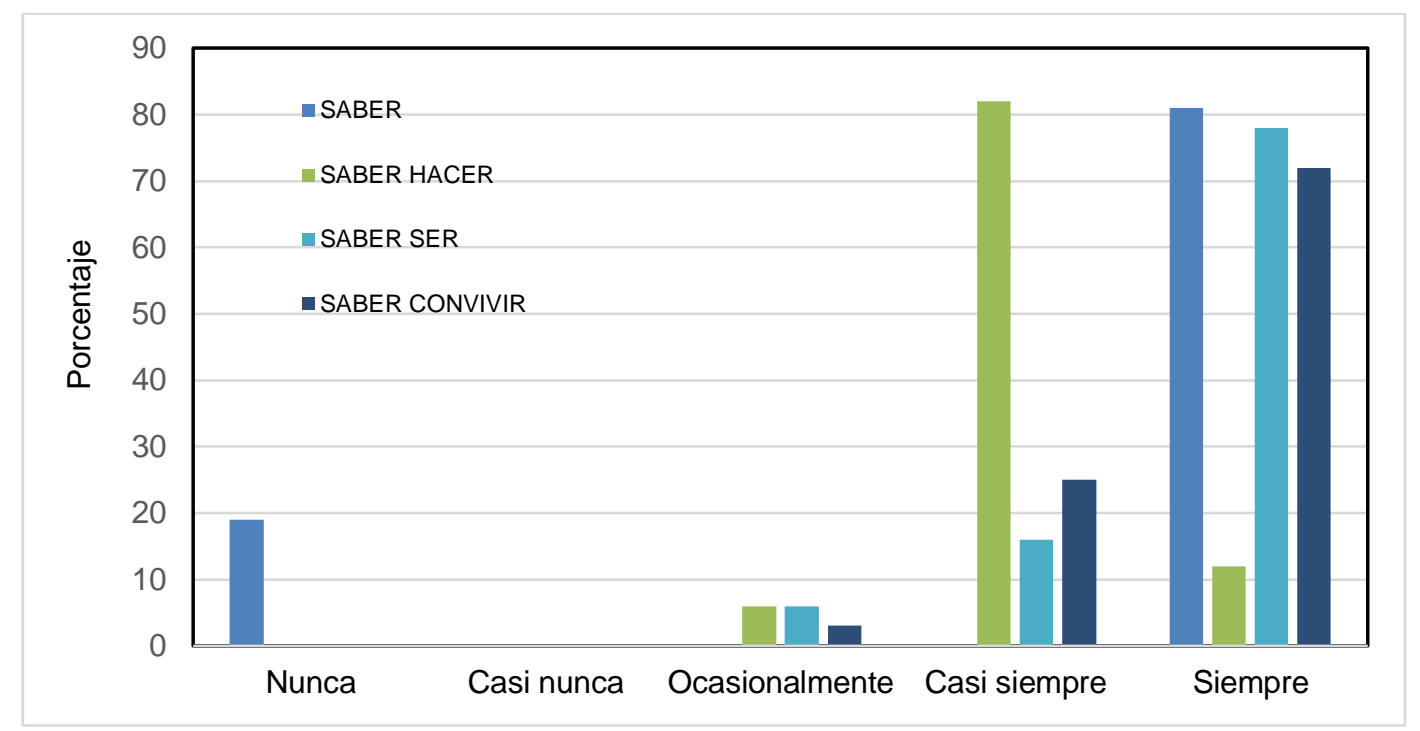

Fig. 1: Consolidado de las dimensiones de competencias del docente inclusivo

El análisis del consolidado de las cuatro dimensiones de competencias se refleja en la categoría Siempre en las dimensiones del Saber, Saber Ser y Saber Convivir, con una apropiación del $81 \%, 51 \%$ y $57 \%$, respectivamente; a diferencia de la dimensión Saber Hacer que recibió una valoración en la dimensión Casi Siempre con un $65 \%$. Es preciso señalar que los docentes de las instituciones educativas oficiales del Distrito de Cartagena, a pesar de haber sido formados en aspectos pedagógicos y didácticos para su desempeño profesoral, son competentes en un promedio del $63 \%$ en el desarrollo de las dimensiones Saber, Saber Ser y Saber Convivir, desde el enfoque de la educación inclusiva en la categoría Siempre, ante estudiantes con necesidades específicas que requieren apoyo educativo diferenciado. Por otro lado, la dimensión Saber Hacer recibió la ponderación de 65 \% en la categoría Casi Siempre. En la dimensión del Saber de competencias fueron evaluados los conocimientos relacionados con la fundamentación teórica de las necesidades educativas especiales, la normatividad inclusiva la pedagogía y didáctica inclusiva y la cultura institucional inclusiva. De forma complementaria, se lograron identificar temáticas a instruir a los docentes relacionados con la Investigación en el aula, a partir de problemáticas en el aprendizaje y la convivencia escolar, la creatividad para el desarrollo de métodos, técnicas y estrategias que favorezcan la inclusión, la Innovación educativa apoyada en TIC, a partir de la sistematización de experiencias significativas, la evaluación y la comunicación asertiva en el manejo de las diferencias.

\section{Resumen estadístico descriptivo de las variables transformadas}

La prueba de Levene es una prueba estadística inferencial utilizada para evaluar la igualdad de las varianzas para una variable calculada para dos o más grupos, donde algunos procedimientos estadísticos comunes asumen que las varianzas de las poblaciones de las que se extraen diferentes muestras son iguales y la prueba de Levene evalúa este supuesto. Si el P-valor resultante de la prueba de Levene es inferior a un cierto nivel de significación (típicamente 0.05), es poco probable que las diferencias obtenidas en las variaciones de la muestra se hayan producido sobre la base de un muestreo aleatorio de una población con varianzas iguales. Por lo tanto, la hipótesis nula de igualdad de varianzas se rechaza y se concluye que hay una diferencia entre las variaciones en la población. Los valores reflejados en la prueba de Leneve de igualdad de varianza en $\mathrm{F}$ en las Dimensiones Saber Hacer, Saber Ser y Saber convivir son superiores a 0,05, por lo tanto, la hipótesis de homogeneidad se acepta debido a que no hay diferencia entre las varianzas de la población. De manera complementaria la prueba "t" de Student por igualdad de medias es un tipo de estadística deductiva, utilizada para determinar si hay una diferencia significativa entre las medias de dos grupos. Con toda la estadística deductiva, asumimos que las variables dependientes tienen una distribución normal. Desde esta afirmación, se crean dos categorías de la variable Saber, consideradas Saber parcial y Saber alto y se comparan con las otras Dimensiones de competencia, definidas como Saber Hacer, Saber Ser y Saber Convivir. 
El análisis de los resultados obtenidos permite deducir que no hay diferencias significativas entre los sujetos que tienen un grado parcial o alto de conocimiento (dimensión Saber), al compararlo con las dimensiones Saber Hacer, Saber Ser y Saber Convivir. De esta forma se deduce que se acepta la hipótesis nula debido a que en términos de igualdad no hay diferencia significativa entre profesores que tienen una alta puntuación en la dimensión del SABER respecto a los profesores que tienen un SABER parcial, debido a que es independiente el nivel de conocimiento sobre inclusión que posean los docentes en relación a las habilidades del saber aplicado, las habilidades humanísticas y de convivencia, para tener un desempeño que facilite los procesos, tanto de los estudiantes con discapacidades como los que poseen talentos excepcionales. En la Tabla 1 se registran las pruebas de muestras independientes de las Dimensiones Saber Hacer, Saber Ser y Saber Convivir, respectivamente.

Tabla 1: Prueba T de muestras independientes de la dimensión Saber, Saber Hacer, Saber Ser y Saber Convivir

\begin{tabular}{|c|c|c|c|c|c|c|c|c|c|c|}
\hline & \multicolumn{2}{|c|}{$\begin{array}{c}\text { Prueba de } \\
\text { Levene de } \\
\text { igualdad de } \\
\text { varianzas }\end{array}$} & \multicolumn{7}{|c|}{ Prueba de t para igualdad de medias } \\
\hline & & \multirow[t]{2}{*}{$F$} & \multirow[t]{2}{*}{ Sig. } & \multirow[t]{2}{*}{$t$} & \multirow[t]{2}{*}{$g l$} & \multirow[t]{2}{*}{$\begin{array}{l}\text { Sig. } \\
\text { (bilateral) }\end{array}$} & \multirow[t]{2}{*}{$\begin{array}{l}\text { Diferencia } \\
\text { de medias }\end{array}$} & \multirow{2}{*}{$\begin{array}{l}\text { Diferencia } \\
\text { de error } \\
\text { estándar }\end{array}$} & \multicolumn{2}{|c|}{$\begin{array}{c}95 \% \text { de intervalo } \\
\text { de confianza de la } \\
\text { diferencia }\end{array}$} \\
\hline & & & & & & & & & Inferior & Superior \\
\hline \multirow{2}{*}{$\begin{array}{l}\text { Dimensión } \\
\text { del Saber } \\
\text { Hacer }\end{array}$} & \begin{tabular}{|l|} 
Se asumen \\
varianzas iguales
\end{tabular} & 1,553 & 0,216 & 0,53 & 88 & 0,598 & 0,051 & 0,096 & $-0,14$ & 0,242 \\
\hline & \begin{tabular}{|l|} 
No se asumen \\
varianzas iguales
\end{tabular} & & & 0,484 & 44,61 & 0,63 & 0,051 & 0,105 & $-0,161$ & 0,262 \\
\hline \multirow{2}{*}{$\begin{array}{l}\text { Dimensión } \\
\text { del Ser }\end{array}$} & \begin{tabular}{|l|} 
Se asumen \\
varianzas iguales
\end{tabular} & 2,062 & 0,155 & $\begin{array}{c}- \\
0,651\end{array}$ & 88 & 0,517 & $-0,072$ & 0,11 & $-0,291$ & 0,147 \\
\hline & $\begin{array}{l}\text { No se asumen } \\
\text { varianzas iguales }\end{array}$ & & & $\begin{array}{c}- \\
0,707\end{array}$ & 68,25 & 0,482 & $-0,072$ & 0,102 & $-0,274$ & 0,131 \\
\hline \multirow{2}{*}{$\begin{array}{l}\text { Dimensión } \\
\text { del } \\
\text { Convivir }\end{array}$} & $\begin{array}{l}\text { Se asumen } \\
\text { varianzas iguales }\end{array}$ & 0,48 & 0,49 & 0,712 & 88 & 0,479 & 0,104 & 0,146 & $-0,186$ & 0,394 \\
\hline & \begin{tabular}{|l|} 
No se asumen \\
varianzas iguales
\end{tabular} & & & 0,69 & 51,09 & 0,493 & 0,104 & 0,151 & $-0,199$ & 0,407 \\
\hline
\end{tabular}

\section{Sistematización de los aportes de los grupos focales}

El objetivo de la actividad desarrollada con los grupos focales consistió en conocer, desde otra mirada, aspectos relacionados con la formación y las competencias de los docentes de básica primaria, vinculados a las Instituciones Educativas Oficiales del distrito de Cartagena. La categorías y subcategorías definidas permitieron conceptualizar en forma adicional las habilidades pedagógicas, psicopedagógicas, neuro psicopedagógicas y psiquiátricas para el aprendizaje en el marco de la educación inclusiva (ver Tabla 2). Se analizaron e interpretaron cualitativamente las apreciaciones de los participantes en la entrevista grupal realizada.

Tabla 2: Categorías y subcategorías de la investigación.

\begin{tabular}{|l|l|l|}
\hline \multicolumn{1}{|c|}{ Categorías } & \multicolumn{1}{|c|}{ Subcategorías } & \multicolumn{1}{|c|}{ Enfoques disciplinares } \\
\hline $\begin{array}{l}\text { Formación del } \\
\text { docente inclusivo }\end{array}$ & Necesidades formativas del docente & $\begin{array}{l}\text { Enfoque pedagógico y psicopedagógico } \\
\text { Enfoque Neuro psicopedagogía } \\
\text { Enfoque psiquiatría para el aprendizaje }\end{array}$ \\
\cline { 2 - 3 } & Dificultades en la práctica docente & \\
\hline $\begin{array}{l}\text { Competencia del } \\
\text { docente inclusivo }\end{array}$ & $\begin{array}{l}\text { Habilidades del docente inclusivo } \\
\text { (Dimensiones Saber y Saber hacer de } \\
\text { competencias) }\end{array}$ & $\begin{array}{l}\text { Enfoque pedagógico y psicopedagógico } \\
\text { Enfoque Neuro psicopedagogía } \\
\text { Enfoque psiquiatría para el aprendizaje }\end{array}$ \\
\cline { 2 - 2 } & $\begin{array}{l}\text { Actitudes del docente inclusivo } \\
\text { (Dimensiones Saber Ser y Saber } \\
\text { Convivir) }\end{array}$ & \\
\hline
\end{tabular}




\section{Perfil del docente de la educación inclusiva}

El perfil del docente que apoya la inclusión lo constituyen dos variables previamente estudiadas identificadas como formación y competencias del docente inclusivo. La variable referenciada como formación del docente inclusivo está constituida por la formación inicial y continua del docente que apoya la inclusión, formación para fortalecer el ejercicio profesoral, formación para atender discapacidades y condiciones excepcionales, formación del docente en áreas de apoyo que facilitan la inclusión y formación en particularidades de la variable en el contexto estudiado. De forma complementaria la variable competencias del docente que apoya la inclusión se presenta organizado por dimensiones, conocidas como Saber, Saber Hacer, Saber Ser y Saber Convivir.

La dimensión del Saber de competencias está conformada por las competencias básicas y profesionales del docente inclusivo y los conocimientos fundamentales de las necesidades específicas, que requieren apoyo educativo diferenciado. La dimensión del Saber Hacer de competencias es un conjunto de habilidades identificadas como actitudes de profesorado en la inclusión, desarrollo de prácticas educativas inclusivas e interculturales, estilos de enseñanza y aprendizaje, experiencias educativas y manejo de conductas. La dimensión del Saber Ser de competencias lo componen un conjunto de elementos tales como el manejo de la ética del cuidado, principios y valores morales, cívicos y habilidades humanísticas y la de dimensión del Saber Convivir de competencias se constituye por un conjunto de habilidades identificadas como manejo de la convivencia en el clima escolar, desarrollo de habilidades sociales en escenarios de inclusión social y manejo del modelo social de discapacidad. En la Tabla 3 se muestran los elementos básicos del perfil del docente inclusivo de básica primaria desde el enfoque cualitativo, asociado a las categorías de formación y competencias, según los enfoques pedagógicos, psicopedagógico, neuro psicopedagógico y psiquiátrico para el aprendizaje.

Tabla 3: Mapa de Relación de Códigos de las Categorías Formación y Competencias del Docente Inclusivo

\begin{tabular}{|c|c|c|}
\hline \multicolumn{3}{|c|}{ Perfil de formación y competencias del docente en el marco de la educación inclusiva } \\
\hline Formación psicopedagógica del docente & $\begin{array}{c}\text { Enfoque } \\
\text { psicopedagógico }\end{array}$ & Habilidades psicopedagógicas del docente \\
\hline Proceso de desarrollo humano & & $\begin{array}{lll}\text { Capacidad para saber } & \text { presentar } \\
\text { asertivamente sus saberes } & \\
\end{array}$ \\
\hline $\begin{array}{l}\text { Procesos psicopedagógicos en estudiantes con } \\
\text { discapacidad y condiciones excepcionales }\end{array}$ & & Capacidad para exponer con claridad \\
\hline $\begin{array}{l}\text { Psicopedagogía social en los contextos escuela, } \\
\text { familia y sociedad en general }\end{array}$ & & $\begin{array}{l}\text { Capacidad para conectar, convencer y } \\
\text { comunicar en diferentes escenarios } \\
\text { educativos a través de técnicas didácticas. }\end{array}$ \\
\hline Formación neuro psicopedagógica del docente & $\begin{array}{l}\text { Enfoque de la neuro } \\
\text { psicopedagogía }\end{array}$ & $\begin{array}{l}\text { Habilidades neuro psicopedagógica del } \\
\text { docente }\end{array}$ \\
\hline \multirow[t]{3}{*}{$\begin{array}{l}\text { Teorías del aprendizaje desde el enfoque de la } \\
\text { psicoterapia }\end{array}$} & & $\begin{array}{l}\text { Capacidad para minimizar las dificultades } \\
\text { de aprendizaje a través de la estimulación }\end{array}$ \\
\hline & & $\begin{array}{l}\text { Capacidad para potenciar las habilidades } \\
\text { del estudiantado }\end{array}$ \\
\hline & & $\begin{array}{l}\text { Capacidad para diferenciar la necesidad } \\
\text { de estimulación, considerando el origen } \\
\text { del problema (orgánico o emocional). }\end{array}$ \\
\hline \multirow[t]{2}{*}{$\begin{array}{l}\text { Técnicas de acción repetida para lograr cambios } \\
\text { cerebrales que incidan en el aprendizaje del } \\
\text { estudiante }\end{array}$} & & $\begin{array}{l}\text { Capacidad para atender nuevas dinámicas } \\
\text { de la enseñanza y el aprendizaje } \\
\text { relacionadas con los procesos mentales } \\
\text { superiores (atención, memoria, función } \\
\text { ejecutiva) }\end{array}$ \\
\hline & & $\begin{array}{l}\text { Capacidad para entender las indicaciones } \\
\text { neuropsicológicas a s situaciones } \\
\text { presentadas en las nuevas dinámicas del } \\
\text { proceso de E-A y saberla aplicar en el } \\
\text { contexto educativo. }\end{array}$ \\
\hline $\begin{array}{l}\text { Técnicas cognitivas - conductuales aplicadas en } \\
\text { el aula con el fin de regular o modificar el } \\
\text { comportamiento del estudiante }\end{array}$ & & $\begin{array}{l}\text { Capacidad para saber plasmar en términos } \\
\text { pedagógicos los procesos mentales } \\
\text { superiores que promuevan la formación } \\
\text { integral de los estudiantes }\end{array}$ \\
\hline
\end{tabular}


Tabla 3: continuación

\begin{tabular}{|c|c|c|}
\hline $\begin{array}{l}\text { Formación docente en psiquiatría para el } \\
\text { aprendizaje }\end{array}$ & $\begin{array}{l}\text { Enfoque de la } \\
\text { psiquiatría para el } \\
\text { aprendizaje }\end{array}$ & $\begin{array}{l}\text { Competencias docentes en psiquiatría } \\
\text { para el aprendizaje }\end{array}$ \\
\hline \multirow[t]{2}{*}{$\begin{array}{l}\text { Patologías más comunes en el contexto escolar } \\
\text { para identificación temprana de sus } \\
\text { características en su acción preventiva a nivel } \\
\text { de salud mental. }\end{array}$} & & $\begin{array}{l}\text { Capacidad para identificar patologías que } \\
\text { requieren adaptaciones curriculares y uso } \\
\text { de herramientas prácticas en el aula de } \\
\text { clases }\end{array}$ \\
\hline & & $\begin{array}{l}\text { Capacidad para aplicar técnicas para } \\
\text { regulación de conductas en los } \\
\text { estudiantes, } \\
\text { distracciones y freno inhibitorio tanto } \\
\text { verbal como motor }\end{array}$ \\
\hline $\begin{array}{l}\text { Comunicación asertiva en la identificación } \\
\text { temprana de las características de las } \\
\text { patologías en informes del proceso de E-A a } \\
\text { padres de familias }\end{array}$ & & $\begin{array}{l}\text { Capacidad para elaborar informes de } \\
\text { conductas asociadas a aspectos } \\
\text { cognitivos }\end{array}$ \\
\hline
\end{tabular}

\section{Perfil del nuevo docente de la educación inclusiva}

En un contexto educativo que valora las diferencias se tiene en cuenta un modelo social de discapacidad y condiciones excepcionales que debe ser apropiado por el docente, de manera que le permita el manejo y evaluación de casos fortuitos de convivencia, caracterizados por prudencia e inteligencia emocional, enmarcado en un proyecto comunitario que responda a una educación para todos a través de liderazgo pedagógico de los docentes. Considerando los enfoques disciplinares involucrados se definen las variables del perfil del docente de la educación inclusiva para el contexto estudiando. La triangulación de los resultados desde los diseños metodológicos cuantitativo y cualitativo permitió definir el perfil del nuevo docente de básica primaria en el marco del enfoque inclusivo (ver Tabla 4).

Tabla 4: Perfil del docente de la educación inclusiva considerando las variables formación y competencias

\begin{tabular}{|c|c|c|}
\hline Formación docente & Enfoques disciplinares & Competencias docente \\
\hline Fundamentos teóricos de la formación inclusiva & \multirow{15}{*}{ Pedagogía y didáctica } & \multirow{15}{*}{$\begin{array}{l}\text { Habilidades pedagógicas y didácticas } \\
\text { inclusivas } \\
\text { (Metodologías innovadoras de } \\
\text { aprendizaje y enseñanza) }\end{array}$} \\
\hline $\begin{array}{l}\text { Discapacidades, trastornos y condiciones } \\
\text { excepcionales }\end{array}$ & & \\
\hline Manejo de la normatividad inclusiva & & \\
\hline Cultura institucional inclusiva & & \\
\hline $\begin{array}{l}\text { Investigación en el marco del contexto educativo } \\
\text { inclusivo }\end{array}$ & & \\
\hline Innovación educativa y TIC & & \\
\hline $\begin{array}{l}\text { Comunicación asertiva en el manejo de las } \\
\text { diferencias }\end{array}$ & & \\
\hline Evaluación desde las diferencias individuales & & \\
\hline Fundamentos teóricos de apoyo psicosocial & & \\
\hline $\begin{array}{l}\text { Fundamentos básicos de la pedagogía } \\
\text { diferencial }\end{array}$ & & \\
\hline Derechos fundamentales de la educación & & \\
\hline Diferencias individuales para el aprendizaje & & \\
\hline $\begin{array}{l}\text { Identificación de las potencialidades de los } \\
\text { estudiantes }\end{array}$ & & \\
\hline Fundamentos básicos de la didáctica inclusiva & & \\
\hline Factores incidentes en la práctica pedagógica & & \\
\hline $\begin{array}{l}\text { Fundamentos básicos del enfoque disciplinar de } \\
\text { la psicopedagogía }\end{array}$ & Psicopedagogía & $\begin{array}{l}\text { Habilidades psicopedagógicas del } \\
\text { docente }\end{array}$ \\
\hline $\begin{array}{l}\text { Fundamentos básicos del enfoque disciplinar de } \\
\text { la neuro psicopedagogía }\end{array}$ & Neuro psicopedagogía & $\begin{array}{l}\text { Habilidades neuro psicopedagógicas } \\
\text { del docente }\end{array}$ \\
\hline $\begin{array}{l}\text { Fundamentos básicos del enfoque disciplinar de } \\
\text { la psiquiatría para el aprendizaje }\end{array}$ & $\begin{array}{l}\text { Psiquiatría para el } \\
\text { aprendizaje }\end{array}$ & $\begin{array}{l}\text { Habilidades docentes de la } \\
\text { psiquiatría para el aprendizaje }\end{array}$ \\
\hline
\end{tabular}


La formación docente en el marco de la educación inclusiva debe responder a los fundamentos teóricos tales como las discapacidades y condiciones excepcionales, normatividad educativa, pedagogía diferenciada, didáctica inclusiva, cultura institucional inclusiva, investigación en el contexto educativo, creatividad, innovación y TIC, comunicación asertiva en el manejo de las diferencias, evaluación desde la diferencia y los fundamentos básicos de los enfoques disciplinares de la pedagogía diferencial, didáctica inclusiva, psicopedagogía, neuro psicopedagogía y psiquiatría para el aprendizaje.

Las competencias docentes deben responder a las necesidades específicas de los estudiantes con habilidades pedagógicas-didácticas, psicopedagógicas, neuro psicopedagógicas y de psiquiatría para el aprendizaje, consolidando el nuevo perfil del docente de la educación inclusiva, donde las habilidades pedagógicas- didácticas deben referirse a metodología innovadoras para el aprendizaje y la enseñanza, así como las psicopedagógicas están relacionadas a la capacidad para saber presentar asertivamente sus saberes, a exponer con claridad y a la capacidad para conectar, convencer y comunicar en diferentes escenarios educativos a través de técnicas didácticas. De igual forma las habilidades neuro psicopedagógicas requeridas deben estar asociadas a la capacidad para minimizar las dificultades de aprendizaje a través de la estimulación, a potenciar las habilidades del estudiantado, a la capacidad para diferenciar la necesidad de estimulación de carácter orgánica o emocional, a atender nuevas dinámicas de la enseñanza y el aprendizaje relacionadas con los procesos mentales superiores(atención, memoria, función ejecutiva), en dar respuesta con explicaciones neuropsicológicas a situaciones presentadas en las nuevas dinámicas del proceso de E-A y a dar instrucciones pedagógicas de los procesos mentales superiores que promuevan la formación integral de los estudiantes. Por último, las habilidades psiquiátricas para el aprendizaje como enfoque disciplinar novedoso que se integra al perfil del docente de la educación inclusiva, se relacionan con la capacidad para identificar patologías que requieren adaptaciones curriculares y uso de herramientas prácticas en el aula de clases, a la aplicación de técnicas para regulación de conductas en los estudiantes, caracterizadas por distracciones y freno inhibitorio tanto verbal como motor y con la elaboración de informes de conductas asociadas a aspectos cognitivos.

\section{DISCUSIÓN}

En el marco de la discusión se presentan en forma separada las categorías del perfil del docente en la educación inclusiva, relacionadas con la formación y competencias. El $63 \%$ de los docentes de las Instituciones Educativas Oficiales del Distrito de Cartagena son competentes en el desarrollo de las dimensiones Saber, Saber Ser y Saber Convivir, desde el enfoque de la educación inclusiva en la categoría "siempre" en su relacionamiento de estudiantes con necesidades específicas que requieren apoyo educativo diferenciado y un $65 \%$ en la dimensión Saber Hacer en la categoría "casi siempre", de igual forma, Orozco y Moriña (2019) le dio relevancia a los saberes, pero más a la práctica profesional, a través de las experiencias pedagógicas, posibilitando la creación y el desarrollo de una relación educativa que atienda a las necesidades individuales y a las particularidades de sus alumnos, dando apoyo a lo experimentado en el aula de clases, considerándolos como espacios abiertos.

El 70,3\% de los docentes encuestados manifestaron haber recibido formación en las áreas de pedagogía y psicología educativa, aspecto anterior reconocido por Domínguez et al. (2016) como se citaron en Alegre y Villar (2019), al sugerir programas psicoeducativos para el desarrollo emocional y las habilidades sintácticas, de lectura, vocabulario y estrategias semánticas para niños y adolescentes, los cuales deben incluir estrategias "implantadas por maestros especialistas en audición y lenguaje que participan con los maestros tutores en la mejora de problemas de conducta y de comprensión del significado de materiales curriculares presentados oralmente en la enseñanza" (p. 21). Los resultados evidencian una mayor proporción en formación recibida por los docentes en la discapacidad intelectual $(27 \%)$, seguido de las sensorial auditiva y visual ( $23 \%$ y $21 \%$, respectivamente), resultados que invitan a cualificar a los docentes en estas y de igual forma, en las demás discapacidades que hoy en día, desde el enfoque inclusivo, pueden estar presente en un aula regular de clases.

Existe la necesidad de avanzar en la educación inclusiva, de manera que permita atender estudiantes con discapacidades significativas, asimismo, Zagona et al. (2017) consideraron que se debe hacer un mayor esfuerzo en lograr que los docentes estén formados y tengan experiencia para implementar prácticas inclusivas que favorezcan la totalidad de los estudiantes, en especial los que presentan dificultades en el proceso de aprendizaje por presentar alguna discapacidad. El $81 \%$ de la población estudiada posee conocimientos sobre necesidades educativas especiales, normatividad inclusiva, pedagogía y didáctica inclusiva y cultura institucional inclusiva, donde la mayor proporción la obtuvo la cultura institucional inclusiva (84\%), seguida por la pedagogía-didáctica inclusiva (83\%) y en menor proporción se ubicaron los conocimientos básicos sobre discapacidades, capacidades y condiciones excepcionales y la normatividad inclusiva (79 \% y $78 \%$, respectivamente); en este sentido, Fernández y Duarte (2016) pusieron en evidencia la importancia del compromiso institucional con el cumplimiento de la normatividad inclusiva; reconociendo la 
importancia de la capacitación de los docentes en el manejo de estudiantes con Necesidades Educativas Especiales (NEE), así como el conocimiento de la comunidad académica respecto a los derechos y posibilidades de acceso y permanencia en la institución educativa de personas en situación de discapacidad.

Relacionada a la variable formación de docentes en la muestra estudiada, la mayor incidencia la presenta la formación en licenciatura (37,4\%). En un nivel similar se encuentran los formados en maestría $(7,7 \%)$ y técnico-tecnológico (7,2\%). Finalmente, en el menor nivel se encuentran los especialistas, los profesionales universitarios y los normalistas, con $4,4 \%$ en cada nivel de formación. Los docentes de básica primaria del país y de igual manera los docentes de las IEO del Distrito de Cartagena están formados para desempeñarse en un aula regular de clases en los niveles de formación detallados con anterioridad. La caracterización de los docentes de la muestra logró identificar que un 4,4\% de los docentes de básica primaria de los 6 centros educativos del Distrito de Cartagena con potencial de ser inclusivas, tiene formación universitaria y a través de cualificación de formación docente han logrado incursionar al sector oficial como tal. Dadas las exigencias de la educación inclusiva requieren formarse en áreas complementarias que la misma naturaleza de la educación de todos para todos exige como tal. Los resultados de la investigación arrojaron que el docente de la educación inclusiva debe tener formación en aspectos psicosocial, investigación, innovación y TIC, comunicación asertiva y evaluación desde las diferencias individuales.

Hoy por hoy los profesionales de la educación requieren ser formados en forma continua dada las dinámicas del mundo y los perfiles de los estudiantes con los que toca interactuar, lo que obliga de igual forma a las universidades con programas de formación inicial y continua a actualizar sus currículos que permitan formar docentes a la luz de los retos del siglo XXI. Aspectos anteriores fueron corroborados con los aportes de Domínguez et al. (2016) citados por Alegre y Villar (2019) al sugerir formación docente en aspectos psicosocial para el desarrollo emocional y las habilidades sintácticas, de lectura, vocabulario y estrategias semánticas para niños(as) y adolescentes. Por último es importante el uso de recursos tecnológicos para apoyar el proceso de E-A. y en este sentido Baldiris et al. (2019), Arroyabe et al. (2018) y Basantes et al (2018), establecen que las herramientas tecnológicas han facilitado la comunicación y a su vez, la comprensión de los numerosos contenidos que se imparten en la formación académica colocando a los docentes en el reto de adquirir las competencias y habilidades necesarias para poder implementarlas con éxito y que éstas se conviertan en una verdadera fuente de progreso para la totalidad de los estudiantes.

Por otra parte, la formación del docente en el desarrollo de habilidades cognitivas y su afectación en estudiantes con dificultades de aprendizaje por factores del entorno y de su desarrollo neuropsicológico, se logran identificar con los aportes de Dávila (2013), al evidenciar en su estudio que el adecuado desarrollo de habilidades cognitivas se da por medio de requisitos importantes para el aprendizaje de habilidades académicas como la lectura y la escritura en los estudiantes. El docente debe estar formado con competencias para facilitar el aprendizaje académico exitoso de niños y niñas, a través de estrategias seleccionadas para este fin. En este sentido se evidencia con el aporte de las voces de los entrevistados que "Se desconocen la forma de abordar situaciones presentadas dentro del aula de clases con estudiantes con y sin diagnósticos de alguna condición especial" y de igual forma afecta el proceso de E-A, afirmaciones como "El no tener herramientas adecuadas para el trabajo con los estudiantes que presentan necesidades educativas especiales ha generado problemas que han incidido en la práctica docente".

Desde el enfoque de la psiquiatría para el aprendizaje, las voces de los entrevistados permitieron identificar los cambios en el apoyo que esta disciplina viene dando desde lo preventivo en la salud mental de los estudiantes y la forma como el docente puede apoyar los procesos dando los primeros auxilios, afirmando que es "necesario la formación del docente en estrategias que propendan por la salud mental de los estudiantes para aplicar en el aula de clases". Así como también "la formación en aplicación de pruebas para atender problemáticas relacionadas con el aprendizaje y la conducta de estudiantes en el contexto escolar".

Sanhueza et al. (2012) manifestaron en las investigaciones realizadas en cuanto a la dimensión SABER de competencias, que "en general, los profesores presentan una actitud positiva hacia la inclusión, [así como en forma contraria], los recursos materiales y el tiempo continúan siendo percibidos por el profesorado como una limitante para el desarrollo de prácticas inclusivas". (p. 884). En este sentido las voces de los entrevistados permiten corroborar lo anterior cuando afirman "El docente de primaria debe ser empático, motivador, integrador, con capacidad de solucionar problemáticas asociadas con el acto pedagógico, ser adaptativo y con formación que facilite los procesos desde la mirada inclusiva". En este orden de ideas, las voces de los entrevistados permiten corroborar lo dicho con anterioridad cuando afirman que "El docente debe ser competente en el diseño de materiales, métodos y entornos de aprendizaje considerando su alcance para todos los estudiantes de un aula de clases", "El docente debe ser competente en el Diseño de Planes individual de Ajustes razonables a través de acciones, adaptaciones y estrategias, apoyos recursos 0 modificaciones necesarias atendiendo las NEE", "Competencias para la potenciación de las habilidades de los estudiantes en el marco de la inclusión y la promoción de rutinas y organización del tiempo" 
Referido a la dimensión de competencias SABER HACER, Sucaticona (2016) afirmó que "la actitud del docente hacia sus estudiantes juega un papel importante en el acto educativo, más que la naturaleza del área curricular que enseña" (p. 5); por ello, considera importante identificar aquellas actitudes relacionadas a través del contacto, lo cual incide favorablemente en el interés del niño/a por participar en la clase. De manera coincidente, los docentes de la muestra representativa fueron evaluados en cuanto al conocimiento básico sobre cultura institucional inclusiva, cuyos resultados evidencian que el $84 \%$ tiene esta dimensión de competencia, poseen una actitud positiva a la inclusión influenciada por la cultura institucional del establecimiento educativo donde se realiza el acto educativo, por lo que se deben mejorar los obstáculos considerados por los docentes cómo el tiempo y los recursos materiales. Desde las voces de los entrevistados se obtuvo que "En el saber hacer el docente que apoya la inclusión debe ser motivador e investigador, en el saber ser debe ser comprometido, en el saber convivir debe ser capaz de interactuar con los estudiantes $y$ otros profesores considerando las diferencias, así como debe potencializar las habilidades y promover la rutina y organización del tiempo", lo que corrobora la anterior afirmación. También debe "manejar pautas en el aula de clases de estudiantes diagnosticados con alguna discapacidad o condiciones excepcionales" $y$ " manejar en técnicas para la intervención emocional de estudiantes con presunción de enfermedad mental'.

En ese ámbito, el $65 \%$ de los docentes conoce que "la persona con capacidades o con talentos excepcionales globales se caracteriza por presentar un desempeño normal en múltiples áreas acompañado por características de precocidad y habilidades cognitivas" (MEN, 2006, p. 17), de manera que los docentes requieren ser competentes en el trabajo, con proyectos de aula que permitan trabajar con estudiantes con discapacidades y a la vez, involucrar los que tienen características de precocidad y habilidades cognitivas.

Según Cádiz et al. (2012), un profesor competente debe conocer bien lo que enseña, pero también el fundamento filosófico de la educación y su propósito para impartir una educación humanizadora con competencias en la dimensión del SABER SER. En los resultados del estudio se concluye que el reconocimiento a la diversidad de todos los estudiantes es un paso importante para hacer realidad la educación inclusiva, especialmente cuando este reconocimiento lo hace la escuela y los docentes en particular. Al respecto, se observa que más del $50 \%$ de los docentes de la muestra poblacional manifestaron que Siempre respetan la diversidad de sus estudiantes, sin hacer diferencia alguna a estudiantes en condición de discapacidad o condiciones excepcionales, lo que se logra confirmar con las voces de los entrevistados cuando afirman que "El docente que apoya la inclusión debe ser investigador, creativo, innovador, lúdico y motivador desde las diferencias". De igual forma las voces de los entrevistados apuntaron a la necesidad de "saber manejar negación y duelo a padres de familia ante casos de diagnóstico de discapacidades".

Relacionado con la dimensión de competencias del SABER CONVIVIR, Muñoz et al. (2014) expresaron la preocupación de hoy en día por promover la convivencia sana y el clima escolar en los centros escolares que han aceptado la inclusión como una realidad en los tiempos actuales, afirmando que actualmente se da un relacionamiento significativo entre la escuela y la familia comprometidas en la formación integral del estudiante, convirtiéndose en una necesidad cuando se trata de estudiantes en condición de discapacidad o condiciones excepcionales. Lo confirman voces de los entrevistados que dicen que "El docente debe ser comunicativo a nivel individual y grupal'. En cuanto a ello, se puede decir que más del $60 \%$ de la muestra poblacional de docente consideró que Siempre es necesario el trabajo conjunto de la escuela y los padres de familias, incluso con la comunidad en general, especialmente en estudiantes con necesidades educativas especiales. Lo anterior permite establecer que los docentes deben adquirir las competencias que les posibiliten promover la convivencia sana y el clima escolar, vinculando en primer orden a la escuela y la familia, y como complemento, al resto de la comunidad educativa, resaltando en sus voces que debe "Poseer autocontrol a los impulsos y saber manejar las emociones frente a situaciones difíciles presentes en el día de hoy" y " Habilidades para trabajar en forma conjunta con la comunidad educativa en general".

Así como más del $60 \%$ de los docentes expresó que "siempre" reconocen el valor de cada uno de sus estudiantes como seres únicos y diferentes, aceptando en gran medida sus particularidades y comprometiéndose a trabajar con ellas, más del $50 \%$ de los docentes de la muestra poblacional manifestaron que "siempre" respetan la diversidad de sus estudiantes, sin hacer diferencia alguna a estudiantes en condición de discapacidad o condiciones excepcionales, así lo considera González et al. (2019) refiriéndose al respeto a la diversidad y a la conexión constante con el alumnado, generando la necesidad de consolidar en el futuro un profesorado que reconozca a los seres humanos como individuos complejos y diversos. En cuanto a ello, se puede decir que más del $60 \%$ de la muestra poblacional de docente consideró que "siempre" es necesario el trabajo conjunto de la escuela y los padres de familias, incluso con la comunidad en general, especialmente ante estudiantes con necesidades educativas especiales. Lo anterior permite establecer que los docentes deben adquirir las competencias que les posibiliten promover la convivencia sana y el clima escolar, vinculando en primer orden a la escuela, la familia, y al resto de la comunidad educativa. 


\section{CONCLUSIONES}

De los resultados mostrados, de su análisis y discusión, se pueden obtener las siguientes conclusiones: 1. La atención a la diversidad debe ser optimizada en las Instituciones Educativas Oficiales del Distrito de Cartagena- Colombia, evidenciándose que se debe mejorar la formación y habilidades del profesorado de básica primaria a fin de ofrecer una educación de calidad para todo el alumnado, considerando sus necesidades específicas que requieren apoyo educativo diferenciado. 2. En el marco de la educación inclusiva es relevante el conocimiento aplicado en situaciones propias con los estudiantes, acompañada de habilidades humanísticas y de convivencia, debido a que en términos de igualdad no hay diferencia significativa entre profesores que tienen una alta puntuación en la dimensión del Saber respecto a los profesores de básica primaria que tienen un Saber parcial, al relacionarlo con las otras dimensiones de competencias Saber Hacer, Saber Ser y Saber Convivir. 3. El perfil del docente de básica primaria desde las variables formación y competencias y los enfoques disciplinares de la pedagogía, didáctica, psicopedagogía, neuro psicopedagogía y psiquiatría para el aprendizaje, en el marco de la educación inclusiva, garantiza el hecho de ubicar estudiantes sin discapacidad con estudiantes con discapacidad, sin inferir en su rendimiento académico, generando beneficios sociales para la totalidad de los estudiantes. 4. Los docentes de básica primaria requieren fortalecer su formación y habilidades en los enfoques disciplinares de la psicopedagogía, neuro psicopedagogía y psiquiatría para el aprendizaje, de manera que puedan dar un apoyo multidisciplinar durante el acto educativo.

\section{AGRADECIMIENTOS}

Este estudio fue realizado con el apoyo institucional de la Secretaría de Educación del Distrito de Cartagena - Colombia y de la Universidad Tecnológica de Bolívar, y expresa los hallazgos obtenidos relacionados con la tesis doctoral "Innovación didáctica y formación del profesorado".

\section{REFERENCIAS}

Adderley, R. J., Hope, M. A., y otros 4 autores, Exploring inclusive practices in primary schools: focusing on children's voices, doi:10.1080/08856257.2014.964580. European Journal of Special Needs Education, 30(1), 106-121. (2015).

Alegre, O., y Villar, L. Relación entre los problemas emocionales y el desarrollo del lenguaje en niños y adolescentes con dificultades auditivas, doi: https://doi.org/10.15366/reice2019.17.1.001. REICE. Revista Iberoamericana sobre Calidad, Eficacia y Cambio en Educación, 17 (1), 5-23 (2019).

Álvarez, E., Álvarez, M., y otros tres autores. Teachers' perception of disruptive behaviour in the classrooms, doi: 10.7334/psicothema2015.215 (2016). Psicothema, 28 (2), 174-180. (2016).

Álvarez, S., Salazar, O.M., Ovalle, D.A. Modelo basado en agentes para la detección de fallas cognitivas en entornos de aprendizaje colaborativo, http://dx.doi.org/10.4067/S0718-07642018000500289. Información Tecnológica. Vol. 29(5), 289-298 (2018).

Arroyave, M.A., Castillo, L.F., e Isaza, G.A. Análisis de la interacción social en patologías mentales por medios computacionales: Caso de estudio asperger y trastorno por déficit de atención. http://dx.doi.org/10.4067/S071807642018000200063. Información Tecnológica. Vol. 29(2), 63-72 (2018).

Baldiris, S., Zervas, P., Fabregat, R., y Sampson. Developing teachers competences for designing inclusive learninge experiences. Educational Technology and Society, ISSN: EISSN-146-4522,19 (1), 17-27. (2016).

Basantes; A.V., Guerra, F.E., Naranjo, M.E.; y Ibadango, D.K. Los lectores de pantalla: herramientas tecnológicas para la inclusión educativa de personas no videntes. http://dx.doi.org/10.4067/S0718-07642018000500081. Información Tecnológica. Vol. 29(5), 81-90 (2018).

Bonilla, Ma., Castro-Carrasco, P. J., y Gómez, V. Cambio de teorías subjetivas docentes ante sus primeras experiencias con estudiantes con síndrome de Down, doi: http://dx.doi.org/10.4067/S0718-07642020000300051. Revista Información tecnológica, 31(3), 51-64. (2020).

Conejeros, M., Gómez, M., y Donoso, E. Perfil docente para alumnos/as con altas capacidades. Magis, Revista Internacional de Investigación en Educación, A Teaching Profile for Gifted Students, 5 (11), 393-411. (2013

Da Fonte, M,A., y Barton-Arwood, S.M. Collaboration of general and special education teachers: Perspectives and strategies. Intervention in School and Clinic, 53(2), 99-106. (2017)

De Boer, A., Jan Pijl, S., y Minnaert, A. Regular primary schoolteachers' attitudes towards inclusive education: a review of the literatura., doi: https://doi.org/10.1080/13603110903030089. International Journal of Inclusive Education, 15. (2011).

Fernández, J. Competencias docentes y educación inclusiva. Revista Electrónica de Investigación Educativa, 15 (2), $82-$ 99. (2013).

Fernández, F., y Duarte, J. Retos de la inclusión académica de personas con discapacidad en una Universidad pública colombiana, doi: 10.4067/S0718-50062016000400011. Revista Formación Universitaria, 9(4), 95-104. (2016). 
Florian, L., y Linklater, H. Preparing teachers for inclusive education: using inclusive pedagogy to enhance teaching and learning for all, doi: http://dx.doi.org/10.1080/0305764X.2010.526588. Cambridge Journal of Education, 40(4), 36.9386(2010).

Gómez, J.A. Evaluación del impacto del modelo acción docente como alternativa pedagógica para el manejo del trastorno disocial escolar desde la perspectiva humanística, http://dx.doi.org/10.4067/S0718-07642018000600143. Información tecnológica. Vol. 29(6), 143-152 (2018)

González, R., Zabalza, M., Medina, Ma., y Medina, A. Modelo de formación Inicial del profesorado de educación infantil: Competencias y creencias para su capacitación. doi: http://dx.doi.org/10.4067/S0718-50062019000200083. Revista Formación Universitaria, 12(2), 83-96. (2019).

Hutzler, Y., Meier, S., Reuker, S., y Zitomer, M. Attitudes and self-efficacy of physical education teachers toward inclusion of children with disabilities: a narrative review of international literature. Physical Education and Sport Pedagogy, 24(3), 249-266. (2019)

Jiménez, F., Lalueza, J., y Fardella, C. Aprendizajes, inclusión y justicia social en entornos educativos multiculturales,. doi: 10.24320/redie.2017.19.3.830. Revista Electrónica de Investigación Educativa, 19(3). (2017).

Kurniawati, F., De Boer, A., Minnaert, A. y Mangunsong, F. Characteristics of primary teacher training programmes on inclusion: A Literature focus, doi: https://doi.org/10.1080/00131881.2014.934555. Educational Research, 56(3), 310-326. (2014).

Lehane, P., y Senior, J. Collaborative teaching: exploring the impact of co-teaching practices on the numeracy attainment of pupils with and without special educational needs. Journal. European Journal of Special Needs Education, 35. (2020).

Liua, Y,, Alexey Bessudnovb, Alison Blackb and Brahm Norwich. School autonomy and educational inclusión of children with special needs: Evidencefrom England. doi: 10.1002/berj.3593. British Educational Research Journal, 46(3), 532-552. (2020).

Majoko, T. Teacher Key Competencies for inclusive education: Tapping pragmatic realities of Zimbabwean special needs, doi: 10.1177/2158244018823455. Education Teachers. SAGE Open, 1-14. (2019).

Medina Rivilla, A. Formación del profesorado - Actividades innovadoras para el dominio de las competencias docentes. Editorial Universitaria Ramón Areces, 1a Edición, ISBN-10 : 8499611311, Madrid, España (2013)

MEN, Ministerio de Educación Nacional. Decreto 1421 del 29 de agosto 2017

Muñoz, M., López, M., y Assaél. Concepciones docentes para responder a la riversidad: ¿Barreras o recursos para la inclusión educativa?. Psioperspectivas, ISSN 1132-6239, 14 (3), 68-79 (2015).

Orozco, I., y Moriña, A. Práctica docente para una pedagogía inclusiva en educación primaria: Las voces del profesorado, doi: https://doi.org/10.17811/rifie.48.3.2019.331-338. Aula Abierta, 48 (3), 331-338. (2019).

Paniagua, M. Marcadores del desarrollo infantil, enfoque neuropsicopedagógico. Instituto de Investigación en Ciencias humanas y la educación, Universidad La Salle Bolivia. Revista Interuniversitaria de Formación del Profesorado, ISSN: 2411-0035, 12 (12), 89-112. (2016).

Rodríguez, M. V., e Hinojo, F. J. Incidencia de los programas de formación pedagógica en el perfil de los profesionales no licenciados en la Facultad de Educación de UNIMINUTO. doi:10.4067/S0718-50062017000500003. Revista Formación Universitaria, 10 (5), 17-28 (2017).

Soldevila, J.; Naranjo, M., y Muntaner, J. Inclusive practices: the role of the support teacher. doi: https://doi.org/10.17811/rifie.46.2.2017.49-55-. Aula inlcusiva (46), 49-56. (2017)

Villarreal, S., García, J., Hernández, H y Steffens, E. Competencias docentes y transformaciones en la educación en la era digital. doi: http://dx.doi.org/10.4067/S0718-50062019000600003. Revista Formación Universitaria, 12 (6), 3-14 (2019).

Zagona, A., Kurth, J., y MacFarland, S. Teachers' Views of their preparation for Inclusive Education and collaboration. doi: d10.1177/0888406417692969. Teacher Education and Special Education, 40(3) 163-178. (2017). 